\title{
The Problem of Induction and the Problem of Free Will
}

\author{
Avijit Lahiri*
}

*email: avijit.lahiri.al@gmail.com; blog (TacitKnowledge): tacit-views.blogspot.com 


\section{Copyright}

'The Problem of Induction and the Problem of Free Will' (an article)

All rights reserved by Avijit Lahiri, author and publisher

Kolkata (India): 20 September, 2020

avijit.lahiri.al@gmail.com 


\begin{abstract}
In this essay I present a point of view for looking at 'free will', with the purpose of interpreting where exactly the freedom lies. For, freedom is what we mean by it. I compare the exercise of free will with the making of inferences, which usually is predominantly inductive in nature. The making of inference and the exercise of free will, both draw upon psychological resources that define our selves. I examine the constitution of the self of an individual, especially the involvement of personal beliefs, personal memories, affects, emotions, and the psychological value-system, all of which distinguish the self of one individual from that of another. The foundational position that I adopt in this essay is that all psychological processes are correlated with corresponding ones involving large scale neural aggregates in the brain, communicating with one another through wavelike modes of excitation and de-excitation. Of central relevance is the value-network around which the affect system is organized, the latter, in turn, being the axis around which is assembled the self, with all its emotional correlates.
\end{abstract}

The self is a complex system. I include a brief outline of what complexity consists of. In reality all systems are complex, for complexity is ubiquitous, and certain parts of nature appear to us to be 'simple' only in certain specific contexts. It is in this background that the issue of determinism is viewed in this essay. Instead of looking at determinism as a grand principle entrenched in nature independent of our interpretation of it, I look at our ability to explain and to predict events and phenomena around us, which is made possible by the existence of causal links running in a complex course that set up correlations between diverse parts of nature, in this way putting the stamp of necessity on these events. However, the complexity of systems limits our ability to explain and to predict to within certain horizons defined by contexts. Our ability to explain and predict in matters relating to acts of free will is similarly limited by the operations of the self that remain hidden from our own awareness. The aspects of necessity and determinism appear to us in the form of reason and rationality that explain and predict only within a limited horizon, while the rest depends on the complex operation of self-linked psychological resources, where the latter appear as contingent in the context of the exercise of free will.

The hallmark of complex systems is the existence of amplifying factors that operate as destabilizing ones, along with inhibiting or stabilizing factors as well that generally 
limit the destabilizing influences to local occurrences, while preserving the global integrity of a system. This complex interplay of destabilizing and stabilizing influences lead to the possibility of an enormous number of distinct modes of behavior that appear as emergent phenomena in complex systems. Looking at the particular case of the self of an individual that guide her actions and thoughts, it is the operation of our emotions, built around the psychological value-system, that provide for the amplifying and inhibiting factors mentioned above. The operation of these self-linked factors stamps our actions and thoughts as contingent ones that do not fit with our concepts of reason and rationality. And this is what provides the basis of our idea of free will. Free will is not 'free' in virtue of exemption from causal links running through all our self-based processes - ones that remain hidden from our awareness, but is free of what is perceived to be 'reason and rationality' based on knowledge and the common pool of beliefs and principles associated with a shared world-view. I give examples, based on hypothetical but plausible scenarios, illustrating the necessary and contingent aspects of free will.

There is never any freedom from the all-pervading causal links representing correlations among all objects, entities, and events in nature. In the midst of all this, the closest thing to freedom that we can have in our life comes with self-examination and self-improvement. The possibility of self-examination appears in the form of specific conjunctions between our complex self-processes and the ceaseless changes of scenario in our external world. This actually makes the emergent phenomenon of selfexamination a matter of chance, but one that keeps on appearing again and again in our life. Once realized, self examination creates possibilities that would not be there in the absence of it, and these possibilities include the enhancement of further self-enrichment and further diversity in the exercise of our free will.

The closest thing to freedom that we can ever have is, thus, to focus our awareness on to our own selves whenever the possibility presents itself, thereby opening a communication that generates further possibilities of 'freedom'. Whether or not we are able to grab at the chance to do so is contingent upon so many things - we never cease to find innumerable instances of our fellowmen making good use of the chance thrown their way by conjunctions of circumstances. 


\section{Contents}

$\begin{array}{lr}\text { Preamble } & 7\end{array}$

$\begin{array}{ll}\text { Inductive inference: a framework } & 10\end{array}$

The primacy of the unconscious . . . . . . . . . . . . . . 11

The use of rules in inference . . . . . . . . . . . . . . . . . 13

Induction: the essential role of choice . . . . . . . . . . . . . . 15

Induction: the external and the internal context . . . . . . . . . . . 16

Induction: the role of beliefs, emotions and affects . . . . . . . . . . . 17

Inductive inference: the cognitive face of self . . . . . . . . . . . . 20

$\begin{array}{ll}\text { Free will } & 22\end{array}$

Alternatives: the yardstick of assessment . . . . . . . . . . . . . 23

Free will: the question of choice and the question of self . . . . . . . . . . 26

A brief look into the psychology of self . . . . . . . . . . . . . 30

Inferring and willing: more on the cognitive and emotion-laden aspects of self 34

Constraint and freedom . . . . . . . . . . . . . . . . 41

Discovery and justification . . . . . . . . . . . . . . . . . 44

The self-network . . . . . . . . . . . . . . . . . 48

The self-network: personal beliefs . . . . . . . . . . . . . . . . 49

The self-network: emotions ................. 51

Self-network: the psychological value-system . . . . . . . . . . . 55

Complex systems: determinism and causation . . . . . . . . . . . 60

Complex systems: a brief overview . . . . . . . . . . . . . 60

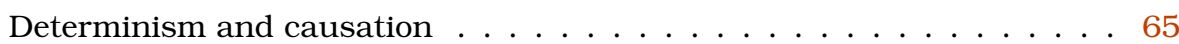

The self as a complex system . . . . . . . . . . . . . 6 69

Free will: the causal expression of self . . . . . . . . . . . . . . 74

Lingering questions: where to locate freedom $\quad 75$

Free will and inductive inference: recalling the basic ideas . . . . . . . . . 75

Learning and self-improvement . . . . . . . . . . . . . . 79

Reasoned exercise of free will: the necessary and the contingent . . . . . . . 90

Summary and concluding words

The problem of induction and the problem of free will . . . . . . . . 95 
From individuals to societies... and on to mankind . . . . . . . . . 101 


\section{Preamble}

All mental activity occurring under given circumstances, including those that can be described as psychological, are based on and are caused by neural processes, where the latter are electrochemical in nature, and are associated with a host of other physiological processes. Assuming that this is an acceptable position to start from, in what sense can we be said to be possessed of free will?

Making a reasonable guess, one can say that some of our mental processes are of the spontaneous type while many others occur in response to specific contexts, where the term 'context' will be seen to have a broad and deep meaning, with a complex texture to it. Apart from and in addition to this distinction between spontaneous and reactive processes, we will also distinguish between unconscious and conscious ones, though the issue of consciousness is once again deep and complex, on which we will have more to say in what follows. Finally, we will have to look at mental processes from another angle as well, distinguishing between those that are primarily emotion-laden in nature and ones that are primarily cognitive.

Such distinctions, especially the one mentioned last, are no doubt contentious, and one should, in all fairness, cover a lot of ground before venturing into an exploration of the issue of free will while starting from such hazardous and dubious premises. In this, I have the following to say.

This essay will primarily be based on commonsense psychology, - whatever that term is worth for. I have no intention of any kind to shed new light on the problem of free will, though I do want to present a point of view or a framework conducive to the understanding of what free will signifies. All I want is to put forward a set of ideas, some of which may not be clear and definitive when considered in isolation, but ones that hang together. Adopting the commonsense approach, I attempt to put together the intended point of view that I hope will be of some value. While ideas and concepts will be introduced on rather vague terms of reference, these will acquire substance as I get along. This essay draws upon several disciplines, and I have tried to ensure that it does not conflict with facts and principles that have been solidly established in the 
mainstream literature on the various subject areas involved.

I may mention that terms like 'commonsense psychology', 'folk psychology', and 'naïve psychology' have generated considerable controversy in psychology and philosophy [37]. However, this essay will not engage with those controversies.

Incidentally, the terms 'emotion-laden' and 'psychological' will be used as ones having largely overlapping meaning when referring to mental processes. I will also use the expression 'self-psychological' as a broadly related one, once I outline the basic idea underlying the concept of self as I understand it. Like many other loosely defined ideas, this will also become clearer as we get going.

My point of departure will be a set of ideas on inductive inference introduced in an earlier monograph of mine [26] since, as we will see, the framework I assembled there has a substantial overlap with what will be outlined in the present essay in respect of free will.

Briefly, inductive inference, which is fundamentally a guessing game, has aspects of a deeply personal nature (relating to the individual making the inference) built into it. Induction is, in a broad sense, a cognitive endeavor, where an act of induction is triggered in response to some kind of cognitive challenge to an individual or a community of individuals. A child becomes suddenly aware that mother is not around (the 'trigger'). She is feeling lost and has to locate her mother (the 'challenge'). She recalls that, on earlier occasions, mother was behind closed doors in an adjoining room (the washroom) and toddles to the door to indulge in a feat of loud and plaintive crying. She has guessed, and guessed right. But the guess could have gone wrong, and her mother could well be chatting with her next-door neighbor this time. But that 'error' would only help the child in broadening her repertoire of hunches, based on which she would be even more adept in guessing her mother's whereabouts the next time around.

In this simple instance of an inductive inference, the role of the personal developmental history of the child is quite apparent. She has not had an experience of her mother chatting with her next-door neighbor. Or it can also be that on the earlier occasion 
when her mother was chatting with her neighbor, the child was on her (the mother's) lap - that most blissful haven for her - and was happily oblivious of much of what was happening around her.

Inductive inference is guessing, but guessing within a context and aided by a context. It is the context that constitutes a vastly complex matrix within which all our psychological and cognitive processes take shape. Context has two aspects to it - the 'external' and the 'internal'. I'll explain these by and by, mentioning here that the internal context is made up of a stupendous mix of psychological resources of the person making the inference, where these resources consist, among many things, of memory, affects, emotions, feelings, beliefs, the knowledge base and, crucially, the reward-punishment network or the psychological 'value-system' innate to her. The theme that will repeatedly be thrust to your attention is that all these - with only the knowledge base constituting an exception of sorts - are deeply, intimately, and uniquely tied to the self of an individual.

Before moving on I want to make brief comments on what I have referred to as the 'knowledge base' and the psychological 'value-system' of a person. The position I adopted in [26] is that the belief system of an individual spans a huge spectrum, at one end of which is located her knowledge base - knowledge is justified belief in the sense that it is inter-subjective and is not person-specific, though, like everything else we talk of, justification is contextual too. A piece of knowledge held by a person (say, the formula $E=m c^{2}$ or, to cite another instance, the fact that influenza is caused by a virus) is certainly not specific to her. What is, however, specific is the set of the particular items of knowledge that make up her knowledge base. For instance, she may be aware that influenza is indeed caused by a virus but may be blissfully ignorant of the formula $E=m c^{2}$. Contrariwise, a physicist residing in an ivory tower all his life (admired and protected, perhaps, by his wife) may be a specialist in matters relating to $E=m c^{2}$ but may not be cognizant of more earthly matters such as the cause of influenza. The knowledge base of a person is most certainly tied to her biography — her developmental history and her emotional makeup or, if you wish, her character trait that constrains what she assimilates into her mind and how. 
The psychological value-system, on the other hand, is something innate to a person, being of relatively early evolutionary origin, but has its basis in a neurochemical setup whose services are, in a manner of speaking, co-opted by the highly ramified and complex emotion-laden and reason-driven mind of an individual as it operates in the current evolutionary stage reached by mankind. Once again, the system is pretty much the same in all individuals, but the way it actually works is incorrigibly tied with the developmental history of each particular person. In the following, we will have to reckon with the existence and activity of this system of extraordinary relevance a great many times in the course of this essay.

With this as background, I'll now outline in the first part of this essay the framework for inductive inference (click to see) that I have spoken of. In the second part, then, we will see if an analogous framework (click here to see) can be built up so as to have an idea of what constitutes free will. We will see that the basic aspects of inductive inference are very much there in the exercise of free will, operating, perhaps, in a different setting. In induction, the center of gravity of the mental processes is tilted towards what can be referred to as the cognitive side of the mind while in the exercise of free will it gets tilted to the emotion-laden side. Having said this I have to add that the two 'sides' are distinct only in our perception because the mind is a single complex system. In a slightly different way of expressing the relation between the two mental activities (the making of an inference and the exercise of free will), we will see that free will is 'free' exclusively in virtue of being determined by the self of an individual, while inductive inference is not exclusively a product of the self. This, of course, will require an explanation of what I mean by 'self. All this will be attended to in the course of this essay.

\section{Inductive inference: a framework}

Inductive inference is commonly looked at as a mode of inference distinct from and antithetical to deductive inference. In fact, however, human inferential activity is of a complex nature, and it is not so easy to distinguish between inductive and deductive modes of inference as these are actually enacted in the human mind. In order to have 
some kind of an understanding of the process of inductive inference, we first set the stage by pointing out the paramount importance of unconscious processes in all types of mental activities and then look at how rules are made use of in inference-making, following this up by highlighting the element of choice in induction, and the role of the context that makes up the complex matrix within which an inference is made. We then briefly outline the relevance of affects, emotions, and beliefs in the making of inductive inference, where the psychological value-system plays an all-important role. All this will be done by way of summarizing what has been explained in greater details in [26], with the exception of the role played by the psychological value-system, based on an innately operative neurochemical system in the brain, which was mentioned there only briefly and in passing. Finally, I will wind up this brief survey of inductive inference by highlighting its deeply personal nature. You will find in [26] a more detailed examination of aspects of inductive inference.

\section{The primacy of the unconscious}

A veritable restructuring of psychology and allied subjects may be said to have taken place during the last forty-odd years in which the primacy of the unconscious has gradually gained acceptance. Though this change has had a continuity with developments in earlier periods, a number of new ways of looking at things and new methods of probing the unconscious have added versatility and vigor to the emerging trends in the recent phase.

Briefly stated, an enormously broad range of complex mental activities are incessantly carried out in the arena of the unconscious mind, which we are not aware of. Even the ones that occur within our focal awareness are associated with a significant degree of participation of unconscious mental processes. Put differently, we are aware of only a minuscule fraction of what goes on in our mind at the level of the so-called 'higher' mental activities.

“...it is evident that consciousness involves linking widely distributed areas of the 
brain into complicated patterns, rather than feeding all the information into a central coordinating region. This is probably why consciousness takes time .... and why most mental activity is conducted below conscious awareness. Neuroscientists have found that the most interesting processes about the human mind - judgments, feelings, motives - typically occur outside of awareness for reasons of efficiency. unconscious mental activities involve not only low-level processes such as perceptual processes but also higher-order psychological processes and states. The adaptive unconscious differs considerably from the Freudian unconscious that was based on repressed unconscious urges and desires, $"[5]$

As amply recognized in the literature, the unconscious mental processes include those commonly thought of as being of 'higher' types (see, for instance, [16]). In particular, much of cognition and inference goes in the unconscious hinterland of the human mind. On the other hand, affects and emotions are also rooted in the unconscious [3], [48], [32].

The cognitive and emotive components of our mental life are linked by our beliefs. Once again, beliefs can be deeply entrenched in the unconscious. Finally, the all-important psychological value-system, also referred to as the reward-punishment system by neuropsychologists, which has a great role to play in the making of decisions, is an innately operating mechanism.

In other words, processes of cognition and inference are played out mostly in the unconscious substratum of the human mind.

Having said this, I must hasten to add that the dichotomous way of looking at mental activities as either conscious or unconscious is not possessed of great merit. The mind is one single entity and what we call mental or psychological processes can all be looked upon as expressions of underlying neural activity. Among these, some occur within the ambit of our awareness, where awareness is itself a psychological epiphenomenon like the rest of our mental processes. Awareness or consciousness is a feature of the mind that is of enormous adaptive value. 


\section{The use of rules in inference}

An inference can, in a sense, be described as a processing of information where one starts from a set of premises and eventually arrives at one or more conclusions. In between, the inferring mind makes use of some set of rules or principles where, generally

speaking, a rule or a principle involves some kind of a relation of implication, i.e., has a structure of the form 'if - then' or 'since - then'.

1. Of course, this and everything else in this essay, is nothing more than a kind of facile description of what appears to go on in the mind, to say nothing of the processes actually occurring in the brain. In particular, the question of representation in the brain is left out of consideration. In what sense and how are rules represented? What relation do the representations bear with the 'if - then' structure that we speak of? These are questions too deep in the context of this essay.

2. It is is a likely supposition that none of the components involved in an inference - the 'premises', the 'conclusions', and the 'rules' - have clear-cut representations in the mind; most things in the mind have associations with most other things, and the starting point, end-point, and the process in between, are likely to be indistinct and tangled by the standards of our spoken language

However, rules can be either extrinsic or intrinsic in nature. When a psychologist analyzes the inferential process of an individual, she (the psychologist) attempts to do so in terms of a set of rules she considers to be relevant for the purpose. For instance, she may think that the subject has made use of the rule of modus ponens, or that she (the subject) has made an inference in accordance with Bayes' principle. The set of rules in terms of which she attempts to describe or evaluate the inferential process of the subject are more-or-less 'objective' in nature, accepted as relevant by other individuals regardless of their personal preferences, and their personal history. In this sense, the extrinsic rules are inter-subjective, and may even be universal, such as the rules mathematics and mathematical logic. 
Within the mind of the individual making the inference, on the other hand, the rules are likely to be of a distinct nature where, in all likelihood, these rules span a wide spectrum. At one end of this spectrum lie the rules accepted to have universal validity; but then as we look towards the other end, we are likely to meet with rules of gradually diminishing universality too. When a housewife calculates the price of a set of grocery items from a price list provided to her for the purpose, the rules of arithmetic she follows are universal. However, when the same person is asked to comment on the current political situation, she makes use of a set of beliefs of a less universal nature (the prime minister is a tyrant, or, the opposition is being treated very shabbily), some of which may be shared by numerous other persons around her, though the extent of sharing may vary as we move to the other end of the spectrum. For instance, "blue eyes indicate a kind heart' - this may be a pretty personal belief by any standards, though there may be a few takers of this 'rule' (or 'principle') too. On the other hand, one can imagine a person who always tries to avoid the number twelve in all his dealings because his son had met with a tragic accident on the twelfth of a month, as a result of which he dreads the number twelve. This represents a purely personal belief of his (however, a dread of the number thirteen would be of a less personal nature), lying at the far opposite end of the spectrum when compared with the universal beliefs. In between these two ends, lie the partly inter-subjective and partly personal beliefs spanning a wide spectrum depending on the extent to which these are shared by persons other than the individual in question. In these instances, the beliefs operate as principles or rules of inference in the minds of people, as they mostly do.

It is this spectrum of rules and principles (mostly based on beliefs held by persons) that is relevant in distinguishing inferential activities of various different types. For instance, the proof of a mathematical theorem may be put together by making use of universal rules alone, while an affectionate father dissuading his impulsive son from engaging in a risky venture may use reasoning of less than universal acceptance, citing certain past instances within the family fold, though his arguments would be acceptable to a sizable proportion of disinterested well-wishers. In this case the inferences put forward by the father may be said to be 'reasoned' one. In other words, the type of inference termed 
'reasoning' makes use of a substantial portion of inter-subjective rules that have a more or less wide acceptance. Moving down the scale one often makes inferences based on 'rules' quite specific to oneself - a mother may insist on spending an unreasonably large sum of money on her son's education, being convinced on the strength of an astrologer's prediction that her child would one day turn out to be a great personality.

As indicated in the above paragraphs, rules of inference are often based on beliefs more or less specific to an individual. And it is precisely this that makes inductive inference a personal affair, deeply linked with affects, emotions, and the workings of her psychological value-system.

\section{Induction: the essential role of choice}

Considered formally, inductive inference differs from deduction in that the conclusion arrived at in an inductive process essentially involves the exercise of choice. On standing at a bus stop for a few minutes you find a crowded bus going your way. You debate with yourself whether to get in the bus and risk an uncomfortable journey, or to wait for the next bus which also goes your way but runs on a different route and is usually less crowded. Finally, you take a plunge into the bus standing in front of you. A sleepy child intending to get on her mother's lap finds her father arriving home with a wonderful toy meant for her. She passes through a few moments of uncertainty before running to her father and snatching the toy. These are simple instances of inductive inference where the choice is a clearly defined one.

The distinction between inductive and deductive inference as regards the matter of choice is, however, somewhat a formal one since choice and decision may be involved in the making of a deductive inference as well (see [26]).

And, incidentally, these are simple instances of the exercise of free will as well. As we will see, making a choice is also supposed to be a feature of the exercise of free will, though the choice is often only vaguely defined and implicit, and will be seen to have a different relevance altogether. As the title of this essay suggests, and as mentioned 
earlier, inferring and willing have a great deal of similarity between them, where the two terms will be used below to denote the acts of making an inductive inference and exercising free will.

Continuing with the issue of the exercise of choice in inferring, it may be noted that a choice is often made with reference to some rule. In order to choose the most bright student of the class, a teacher commonly follows the 'rule' of adding up the marks scored by each student on all the class tests taken during the recently concluded session, and spotting the student with the highest aggregate score. This is a clearly formulated rule that will find acceptance by a large section of her peers. However, it may not be a universally accepted rule by all teachers in the community. For instance, one may be of the opinion that being 'bright' may not be synonymous with being the top scorer in class tests.

One is confronted here with the issue of the wide spectrum of 'rules' referred to in the last section ( click to see). The big question that has to be answered is: how is a choice exercised? Can it be decided by chance? Or, does an individual oftentimes makes tacit use of some rule or other where the rule may be of an intimately personal nature, rooted in the unconscious mind? I have dealt with these questions to the best of my own understanding in [26] in the context of inductive inference. In the present essay now, we will face similar questions in the context of the exercise of free will. But we will have to wait some more before engaging with the deeply contentious issue of free will.

\section{Induction: the external and the internal context}

Speaking in a literal vein, the external context of an inference is the world 'out there' from which the cognitive system (a human mind for the purpose of the present essay) receives myriad inputs in various forms, while the internal context is set by the entire psychological canvass in which the mental processes take shape, based on a hugely complex neurochemical set-up in the brain, supplemented by physiological process in other parts of the body. 
This, of course, is too general a statement to be of any real value in understanding the process of inductive inference. The all-important issue of the context in inductive inference has been examined in [26] in more concrete terms.

Having lived in the city of Kolkata all my life and having found all crows in this city to be black, I infer that all crows are black. Here the external context is set by visual inputs from innumerable birds perched on innumerable trees and projections from buildings, while the internal context consists of psychological resources contributing to the generation of beliefs based on category formation ('crow', 'black') by means of association resulting from covariation of visual inputs. Even this is a very facile and coarse description of what happens in my mind in leading to the conclusion in question, not to speak of the myriads of neural and chemical signals that were generated and propagated from place to place in my brain and body in the formation of the belief. What is important is that all these neurochemical processes and their psychological counterparts depend crucially on results of processes that occurred in the past - associations, memories, and little beliefs, all of which provide a backdrop for the production of the current belief. As a matter of pure logic I could, for instance, conclude that all the crows in the city of Kolkata are black while some of the crows in London are white. But inferences are not plucked from thin air by the exercise of logic, they are formed in the context of past inferences, regularities observed in the past, lessons drawn from false inferences - all of which hugely constrain the conclusions of the current inferential process.

And this brings me to the next item in this list of factors of basic relevance in inductive inference - the role of beliefs, emotions, and affects.

\section{Induction: the role of beliefs, emotions and affects}

Inductive inference essentially involves the making of decisions - decisions to choose from alternatives.

An inferential process is, in a sense, analogous to the sequential processing of information in the execution of a computer program - only much more tangled, much more 
diffuse, and much more constrained and aided by a huge backdrop of psychological resources, generated from past processes, forming an internal context. Like a computer program, it proceeds, in part, in a kind of linear sequence, and then the process branches out, making it imperative to decide which route to follow. Here the inferring mind takes up each of the alternatives (either one at a time or, perhaps, all of those in parallel) and engages in counterfactual thinking: supposing I choose this, what could be the consequences? How would these consequences compare with those following from this other choice? Here the mind needs to judge: how does one possible result compare with another?

Let me start from the supposedly sequential part of the inferential process. Here the question of the use of rules comes up. And, I have mooted the idea that rules can be of an intimately personal nature, rooted deeply in the unconscious. A rule is some kind of a belief ('if this then that') and, as I have hinted, beliefs are strange things in psychology [7]. Belief is half-formed or ill-formed knowledge, based on experience, hearsay and fancy, and all the innumerable beliefs lodged in the mind of an individual form a great web or network that is held together only partly by evidence and solid veracity, but mostly by the force of emotions. The more tightly a belief is held by the influence of emotion, the less justification it needs from evidence and confirmation. It is in virtue of the emotional component of a belief ([31]) that the latter propels us into action. Knowledge is passive, but belief is an activating influence. My knowledge of the truth of the equation $E=m c^{2}$ does not cause me to be febrile and vehement (except, perhaps, in a situation such as the one where I believe that I can derive a consequence of the equation hitherto unknown to the scientific community), but my belief that capitalism is at the root of all our current social problems is likely to make me into a political activist and a demagogue.

Emotions, in turn, are associated with affects and feelings. Affects are innate neurochemical processes of relatively early evolutionary origin that may be of a number of basic types, helping us to respond effectively to situations of various descriptions, being a basic adaptive mechanism helping us to classify the events and situations of this world - a coarse but highly efficacious classification. What is more, the affects are tied to the psychological value-system innately implanted in the mind - a system making 
use of neural aggregates and chemical molecules involved in assigning positive or negative (pleasant or unpleasant) value to events and experiences with which they are stored in the memory (see, for instance, [23], [24]). Emotions, in comparison, are formed in the developmental process of an individual out of these memories colored by classifications and values, and are associated with every new experience in life. In some of the cases the emotional associations are strong while in some others these may be feeble and almost non-existent. Affects and emotions, in their turn, generate feelings - the conscious awareness of something relevant or important happening within and around us. In summary, affects, emotions and feelings, along with the psychological value-system, form a tightly knit complex mechanism that forms the core of our psychological life.

Our mental life is part cognitive and part emotional and, as I have mentioned above, the vast web of beliefs ties the two together. Many of our beliefs being rules of an 'ifthen' type (if a ruling clique acquires dictatorial power then it will exploit the poor people of the land), are made use of in sequential processes involved in an inference. Some of the beliefs are in the nature of heuristics - little bits of inferential rules spontaneously generated in the mind and made use of, as it were, on the fly during the inferential process (chess heuristics, for instance). Heuristics constitute a great intuitive asset in an inferential process but, at the same time, may have the hazardous effect of making the inference fallible. Briefly, heuristics are ready-made rules made use of in an inferential process.

We come now to those crucial phases in inference where the linear sequential process branches out to more than one possible paths. Such a juncture involves a deep dilemma whenever the right course cannot be determined solely by means of rules of universal validity (such as the rules of mathematical logic) or by ones of a non-universal but widely inter-subjective nature (whatever hurts a person is to be avoided at all costs). What keeps the inferential process going in the face of such a dilemma is that amazing complex of resources made up of affects,emotions, and the psychological value-system. When the mind takes up the counterfactual course and follows the likely consequences of the various possible alternatives (each of which may involve sequential reasoning or may again fork out to numerous branches), each of the competing branches gets 
stamped, in a manner of speaking, with a score (much like the scores achieved by students in a class test, though not explicitly by numbers) and an emotional coloring (the latter somewhat like the teachers' comments attached to the score-cards of students). In the final analysis, it is this value score and the emotional coloring that acts like an effective comparison between the possible alternatives, based on which the inferring mind arrives at a decision. The decision, of course, is not necessarily a solidly grounded one in terms of logic and of future evidence-based tests, but it is what the mind settles for, mostly at an unconscious level ([9], [43]). While the package made up of beliefs, emotions, and affects acts in combination with a huge complex of other psychological resources (including ones relating to conscious deductive reasoning), it constitutes in itself the truly amazing core of inductive inference.

\section{Inductive inference: the cognitive face of self}

This completes the brief and sketchy outline of how inductive inference is enacted in the human mind - those aspects of it that I consider relevant in the context of this present essay. What stands out from these few paragraphs is that inductive inference is the cognitive process thoroughly imbued with profoundly personal psychological resources, mostly operative within the unconscious hinterland of the mind. This brings up the question of mental processes guided by the complex and elaborate mental structure constituting the self of an individual.

In the next part, we will take a plunge at working our way through the enigma referred to as free will. It is an enigma in the sense that the name we call it by is seemingly in conflict with the doctrine of determinism. We will see why a big chunk of the mystery of determinism versus free will is more apparent than real while appreciating, at the same time, why free will is a really deep thing in philosophy and psychology - mostly because it is uniquely generated by the self. In this, the exercise of free will ('willing') and the making of inductive inference ('inferring') are two manifestations of the same basic psychological process: the former having an emotion-laden (or 'psychological') orientation and the latter a more cognitive one. Oftentimes, an inductive inference itself 
constitutes an instance of the exercise of free will. This, in particular, is what happens when a scientist comes out with a supremely creative act of hypothesis formation (or of abduction, as it is often referred to). The inferential act of hypothesis formation (spacetime is curved, or, radiation is made up of energy quanta) engaged in by a scientist has its analogue in the creative act of a painter, a musician, or a poet: the creative endeavor in each case is uniquely self-driven.

It is this basic position that we adopt in the present essay. As promised, we will, in the next part of it, expound the idea that the exercise of free will is indeed entirely analogous to the making of inductive inference when looked at as a psychological process. In this, we will come to look at the psychological formation referred to as the 'self. We will come to appreciate how the self is more like a complex network of structures and processes that evolves throughout the developmental history of an individual, made up of memories, beliefs, desires, propensities, emotions, feelings, fantasies, and the workings of a psychological valuing system, all unique to that person. It is this complex network of psychological resources that 'determines' how an individual makes an inference (inductive inference, that is) and also how the same individual exercises her free will. We will look at the tricky and slippery concept of 'determinism' in the context of a system as complex as the self when the familiar connotations of the term take on strange aspects and will see how the idea of causation assumes a greater degree of relevance. Free will is certainly subject to the eternally flowing turbulent stream of causation, as is inductive inference, but is far less compatible with the straitjacket of the commonly accepted notion of determinism.

This, of course, is a point of view (a framework, if you will) to look at the issue of free will that one can accept or turn away from, but not one that can be fruitfully argued for or against. In the rest of this essay, I will try to outline my take on it. 


\section{Free will}

The issue of free will is known for the huge volume of literature it has produced on the question of whether human will is truly 'free' or is under the shackles of 'determinism' (see [12], [20] for background). Is freedom of will compatible with determinism, or is it not?

In the course of the incessant mental activities of an individual, there arise junctures when a person seems to have before him alternative courses he can choose from. These alternatives can be a number of possible actions or of possible streams of mental activity as well.

A footballer, in the course of engaging in his daily fitness program, skips the gym and, instead, takes the option of doing a longer-than-usual stretch of jogging. He can be said to have chosen the option of jogging over the other option of stepping into the gym, and this can be cited as an instance of exercise of free will.

A group of students, on getting a day off from their classes, left their hostel building and headed to the nearby sea-beach for an extended session of beach volleyball, while one of them left the group and chose to take a bus home to spend a quiet day with his parents and sister. He seems to have obviously made a choice, and has exercised his free will. As for the group of his friends headed to the beach, an individual member of the group is not likely to be said to have made a choice, though the group as whole has certainly made one since it could equally well have chosen to go to a movie, or to an open-air restaurant, or to indulge in any of a number of other possible group activities.

Sitting in my study in a rainy evening, I engage in anxious brooding over the possibility of my son meeting with some kind of a mishap during his cross-country drive in inclement weather in complete defiance to my earlier suggestion of desisting from the drive. I had started off with thinking about a political commentary that a local magazine had requested me to write for them, but then somewhere along the line I 'chose' to engage in the fitful brooding in preference to pursuing my political thoughts. 
I will not continue with further instances of exercise of free will for obvious reasons, but will only note that, as the above examples illustrate, free will is commonly supposed to be 'free' in the sense of being associated with the exercise of choice from among alternatives. At times, the question of intent comes up - does a person, in the exercise of free will, in some sense examine the options before him and make a choice by intent? The instance of the homesick student is a case in point since it is likely that he chose to spend time with his family after deliberating upon the other option of accompanying his group of friends. The instance of the anxious father, on the other hand, is indicative of no such deliberation while that of the footballer doing the round of jogging may be supposed to have involved some marginal deliberation, if at all.

The matter of alternatives, the matter of choice, and the one of deliberation and intent - these are some of the supposed features associated with the exercise of free will. In the following, we will examine all these numerous features and will venture into a number of deeper issues that help us appreciate the specific sense in which free will can be said to be 'free', and the sense in which it can be said to involve a 'choice' from among 'alternatives', recalling the case of inductive inference where too an analogous question of choice comes up. In the process, the question of intent will get settled as being somewhat of a secondary one.

\section{Alternatives: the yardstick of assessment}

It might seem that the question of alternatives needs no clarification. That the exercise of free will involves a choice from among alternatives doesn't seem to be in doubt, and the common perception is that it is the other question of compatibility with determinism that deserves a greater degree of scrutiny. We will see in our own way what that other question involves, but will not let go of this issue of alternatives and the exercise of choice as one of less relevance.

The first question we will raise is, alternatives according to whose assessment? And, choice by whom, or by which entity? The latter question may sound silly, but we will

see what sense we can impart to it. We turn, then, to the question of which agent 
identifies the possible alternatives involved in an instance of willing (recall that this is the abbreviation for 'exercise of free will' that we have settled for)? Significantly, a person's action is often described as a choice from among possible alternatives not by the person himself, but by others looking at and assessing the action. True, the person himself may at times assess his own action as one involving a choice, but here again his own list of the alternatives would often not agree with the list that some other individual may come up with. A mother preparing to serve her child with dinner is unlikely to agree that her act is one of making a choice from among possible alternatives, but the child's father may think otherwise. He may seriously entertain the idea that a possible alternative would be for all three of them to sit watching a TV show that the child is fond of before she (the child) is made to dine and retire for the night.

It is significant indeed that different individuals are likely to come up with different lists of the possible alternatives from among which a person makes a choice while exercising her free will. Literally speaking, one can think up of an infinite number of alternatives to a supposed act of willing by an individual. When considered without reference to some given context, a person may be said to have made a choice from an infinity of possibilities. The loving mother could, for instance, go jogging in the night instead of serving dinner to her child. So, clearly, something more specific is involved in assessing the possible alternatives in an exercise of free will. As I understand it, that 'something' lies in the context in which the willing is enacted, and the rules, or the standards invoked in making an assessment of the possible alternatives. I will take up the question of standards first.

When a husband, after some deliberation, agrees with his wife's action of making their child sit for dinner and sending her to bed without further delay, he is clearly invoking the standards that apply to a child and not to an adult, since the standards by which he would assess his wife's decision (an act of free will on her part) regarding the time for the two of them (wife and husband) to sit for dinner, and the possible alternatives to her choice of the dinner time (sitting through a TV show first, for instance) would be quite different. 
Invoking some standard of assessment, often involves the use of some 'rules', or some kind of 'logic' for the same. Suppose that, on questioning your son regarding an incident in the playing ground, you learn that he has beaten a friend of his, which makes you think as to whether to be strict or lenient in punishing him. The choice favoring a heavy punishment is possibly based on your earlier injunction to him that he should never hurt another person. On the other hand, a light punishment would be indicated on the 'logic' that this world is a tough place and everybody has the right to fend for himself when involved in a dispute. A completely different 'logic' points to a third and distinct possible course in the exercise of your free will, namely, the one that friendly but firm and frank discussion with a child is always to be preferred over punishment and, on adopting this point of view, you may then ponder over alternatives as to how best to carry out the discussion.

But, these are all in the nature of possible principles that might guide the mother of an errant child in dealing with him. An outsider looking at the situation can conceivably think of still other possibilities and still other 'principles' that she (the mother) can choose from in exercising her will. The relevant question that comes up here is, does the mother actually make a choice from among all these various principles telling her which one to follow and then decide which course of action to adopt? It would be a very exceptional mother indeed who would deliberate over all these possible approaches and then decide upon how best to deal with her child. More likely than not, her action (the result of exercise of her free will) would involve only a minimal deliberative component and would come about, to all intents and purposes, almost spontaneously. However, though apparently spontaneous, it would at the same time involve a complex interplay of quite a few factors, which she would mostly not be aware of.

At this point, we will not pursue further how an act of willing may be interpreted by an onlooker as one involving a choice from alternatives and how the onlooker sets out to invoke rules of logic (not any strict or rigorous logic but some loosely patched up 'logic' that we commonly employ in daily acts of willing). Because there may be thousands of possible interpretations of an act of willing when looked at from the point of view of an external agent. Put differently, an act of willing is done in some context, and the context 
is judged in various different ways by different persons.

As I indicated in earlier sections (click here and here to see), the context in which an act of inferring or willing is done has an external and an internal aspect to it, where the former is, to some extent, independent of the person involved, being more or less the same for different individuals that may be imagined, each in turn, to be engaged in the act. The internal context, on the other hand, differs vastly from one individual to another. Having said this, I must hasten to added that the separation between the external and the internal does not come cut and dried, but this I am inclined to gloss over for now.

This is of fundamental relevance for our purpose: given the same external context, it is almost certain that different individuals would exercise their will differently because of the stupendous difference in their internal psychological resources. And, it is this difference that makes us say that an act of willing is a 'free' one, since this is really what makes the act of willing look like a choice from among alternatives.

I repeat that the internal psychological resources of an individual make up a system of great complexity. And here again, one part of the system can be said to be common to various different persons while the remaining part is of crucial significance for our present purpose: it constitutes the self of an individual.

\section{Free will: the question of choice and the question of self}

On a pleasant evening I find myself taking a walk along a crowded street and, on finding a bookstore I favor, enter into the display room for browsing through their latest acquisitions. My younger brother would, under similar circumstances, visit a nearby restaurant to relax and spend time. My adolescent son, on the other hand, would take the 'option' of strolling to the riverside and meet his group of friends there.

It is conceivable that I deliberated between the alternatives of the bookstore and the restaurant before opting for the former, and that my younger brother wold also similarly 
weigh his options before acting the way he is supposed to. However, none of us would even think of the other 'option' of walking off to the riverside. As I said, there can conceivably be an infinite number of alternatives from among which one can be said to choose while exercising his free will, but only so many of those are actually relevant in a given context.

For instance, in the case of me entering the bookstore, my act of willing can be described as one of making a choice between two (or more, including a few others that may have been available under the given circumstances) alternatives, and my brother's act would also be assessed similarly. But the possible alternative of strolling to the riverside (known to be frequented by the younger and more boisterous lot of the town) would not be counted in our case. We two being of similar general disposition (similar cultural and family background, similar age), the actual choices made by us are counted as possible alternatives from among which each of us would chose individually. What is important here is that different individuals with similar dispositions would act differently and this difference (among the actions of a number of individuals placed under similar circumstances) is what is said to constitute the set of possible alternatives. It does not matter in this description whether some particular individual, in exercising his will by acting in some particular way, actually weighs between these alternatives.

In other words, the matter of 'choice' is, in a manner of speaking, funny and strange. Suppose that, in a given external contest, three persons $\mathrm{X}, \mathrm{Y}$, and $\mathrm{Z}$, of similar disposition, in exercising their will, perform acts $\mathrm{A}, \mathrm{B}$, and $\mathrm{C}$. The question that comes up is, does $\mathrm{X}$, in performing the act $\mathrm{A}$, actually weigh the options $\mathrm{A}, \mathrm{B}$, and $\mathrm{C}$ as possible alternatives? Why should X be said to have 'chosen' between A, B, and C in actually performing the act $\mathrm{A}$ ? What does it matter to her how some other individuals $(\mathrm{Y}, \mathrm{Z})$ might act under similar circumstances?

Looked at this way, the matter of 'making a choice from among alternatives' does indeed appear funny and strange. Such a 'choice' only appears to be incompatible with determinism since the 'alternatives' cannot really be said to have featured in the mental processes of $\mathrm{X}$ : what $\mathrm{X}$ does as an individual can have nothing to do with what other 
individuals $(\mathrm{Y}, \mathrm{Z})$ might possibly do.

A deeper view to the determinism issue lies in observing that the other individuals $\mathrm{Y}, \mathrm{Z}$ (and still many others) potentially reside in X herself. Put differently, the psychological resources of an individual that make up her internal context in the act of an inference or exercise of will can be looked upon as a composite whole of two parts - one that she possesses in common with many others, and the other that is unique to her.

If I care to examine my (unjustified) belief that women are inferior to men, I will find that many others in my community or in the world at large (unfortunately) share the same general belief. Be that as it may, my own belief is colored with other beliefs specifically my own, along with memories, experiences, emotions, and value judgments, all making up a complex network unique to myself. In other words, any and every psychological resource that I may have within me has a dual identity - one that is shared, and another that uniquely belongs to my own self. The shared part of my complex psychological system looks at things one way, while the other part that belongs to my own self 'perceives' otherwise. Of course, it is only notionally that the two 'perceptions' can be distinguished and, at the end of the day, there is one single perception that differs from person to person. The perceptions of $\mathrm{X}, \mathrm{Y}$, and $\mathrm{Z}$ looking at a tree certainly have something in common while each has memories and emotions uniquely her own that make one of the three pass by the tree without looking at it a second time, another to ponder briefly over its sublimity and grandeur, and the third to go sit under it, recalling nostalgic memories of sitting under a similar tree in bygone days, perhaps in agreeable company.

Significantly, it is the uniquely individual part of the internal mental resources that makes each person act the way that she actually does. Two distinct individuals might appear to act the same way - perhaps with both spending some time sitting under the tree though, here again, the two may have entirely different trains of thought running in them.

In reality, the 'alternatives' exist only as abstract ones when one looks at some given 
external context from the perspective of the shared mental resources of an interpersonal nature alone, with total disregard of the uniquely individual resources that make a person actually follow some course of action with all its associated idiosyncrasies. Looking at a tree standing in front of me I can think of many different things in virtue of my shared world-view such as how a tree is a gift of nature, or how green and densely grown its leaves are or, say, how much of cellulose there is in its trunk, but none of these in itself can be responsible for the particular way I respond to the sight of the tree. As we saw, even when two different individuals appear to respond similarly by taking time off to go sit under it, the details of their response are likely to differ markedly. Even if an individual does make some deliberations of an entirely interpersonal nature, relying only on what is known to be shared by others in the community, the specific aspects of her action cannot be accounted for in terms of those deliberations alone.

The actual action engaged in by an individual may have little to do with such abstract deliberations of an interpersonal nature, and is more likely to result from memories, beliefs, and propensities generated in the course of her own developmental history. As I said, it is too much of an abstraction to even notionally isolate shared interpersonal aspects of an individual's mental resources from the uniquely individual ones and, in as much as one does engage in such an abstraction, one comes up with the possibility of deliberation among alternatives, but such deliberation can have only a marginal role in the actual realization of an action by way of exercise of will. In other words, willing is incorrigibly conditioned by the self of an individual. It then behooves us to examine what constitutes this strange and deeply enigmatic entity that we refer to as 'self. We will have a first brief look at the idea of self in the next section (to be found here), when we will see that the self may get expressed in two modes that one may provisionally distinguish between - 'provisionally' in the sense that not too much is to be read into the distinction.

The two aspects being referred to are the cognitive and the emotion-laden aspects of the self, to be discussed below.

And, it is in this context that one can speak of a difference of sorts between inferring 
and willing that I will come to in a later section (click to see).

\section{A brief look into the psychology of self}

What goes by the name of self is actually an elaborate and intricate psychological network that keeps on evolving throughout the developmental history of an individual.

One has to distinguish between self as a psychological entity, the concept of self, and one's awareness of self. When I write an essay on the self as a psychological entity, it is the concept of self that I am sharing with my prospective readers. When I engage in an act of willing, it the self as a psychological entity that makes me do so. And finally, when I try to look at what made me engage in a certain course of action, I am being aware of the doings of my own self.

Being aware of one's self is an act of consciousness. I can be conscious of this and that as need be, and in the same vein, I can be conscious of my own self. But it is not consciousness that I am concerned with right now. As my understanding goes, the involvement of consciousness in the exercise of free will is, in a relative sense, of less than primary relevance, but the involvement of 'self' is certainly not - indeed, it is of central relevance. Looked at as psychological entities, consciousness presupposes at least some development of the self-network, but it is itself no pre-requisite for self. While consciousness is certainly involved in some acts of free will, it is always accompanied with a great deal of unconscious involvement of the self-network - indeed, consciousness itself is a part of that network. However, at the end of the day, one cannot be too dismissive of the role of consciousness in the exercise of free will, as we will see in the concluding part of this essay ( click to see).

This brings us back to the question of self and what exactly it stands for in the acts of willing (i.e., the ones of exercise of free will) of an individual.

The formation of self as a psychological entity begins with the exchange of signals between the brain and various other parts of the body that constantly upgrades the brain 
about the continued well-being of the body, and that make possible the setting up of remedial measures whenever that well-being (the 'homeostatic condition' as it is at times referred to) is under threat. This also leads to the assembly of a network responsible for distinguishing the body of the individual concerned from the rest of the world. Beginning with the activation of a neural network endowed with these two major capacities there occurs a long journey whereby the self keeps on taking shape as a complex psychological entity through innumerable experiences gone through by an individual [8].

The capacities of the brain and the various structures therein are, in a major way, inherited, having gone through a long process of development in biological evolution. What is specific in the developmental process of an individual is the setting up of interactions (principally of an associative nature) among large groups of neurons, mediated by a set of chemical secretions of vital importance, whereby major neural assemblies act upon one another by means of wavelike synchronous signals of an electrochemical nature sloshing their way among these assemblies, while direct interactions through neural pathways also play a role.

This, then, constitutes the basis of our psychological life - one that I adopt as the foundational hypothesis of all that is written in this essay of mine: all mental resources, events, and processes are based on mutual action among the large scale neural assemblies. While individual neurons numbering several thousand millions at a rough count are certainly the ultimate units of brain functioning, psychological phenomena arise from and can be associated with the activities of the large scale neural assemblies and their interactions with one another. Current studies in neuropsychology that I am aware of seem to support this view. While the individual neurons are the microscopic units making up the brain, one has to look at the macroscopic neural aggregates to correlate psychological phenomena with neural activity (see, for instance, [22]). Mental activities making up our psychological life emerge as epiphenomena arising from the activities of the neural aggregates.

A vast literature exists on the neural basis of psychological phenomena, based on current experimental and clinical methods which are already quite advanced and ef- 
fective from the point of view of understanding the neural basis of various possible psychological processes. The only concern - a major one in this regard - is that of the techniques possibly turning into ones of an insidiously invasive nature and ones, moreover, tending to compromise the autonomy and privacy of the human mind, perhaps the ultimate asset that humankind can ever possess.

The activity of the neural assemblies is much like the large number of institutions of various categories making up a complex social structure, where the institutions operate autonomously and, at the same time, communicate by means of signals of diverse kinds (the radio signals, TV signals, signals flowing through the internet channels, and ones handled by satellites, spoken words, written messages and documents), thereby making possible a stupendous proliferation of the types of possible social phenomena.

The self of an individual is a network of such interacting neural assemblies whose function it is to make a map of whatever is specific and peculiar to that individual. It keeps on being formed and re-formed through every experience in the life of a person, posting a flag in the memory of that experience such that whenever that experience is recalled the flag activates the self-network, and certain emotions and feelings are generated. Or, for instance, whenever a current event either goes against or supports some idiosyncratic belief of the person, the self-network again generates a set of emotions and feelings, by means of which the person reacts to the event.

The major components of the self-network are beliefs, emotions, and feelings that interact with neural signals originating in current perceptions and revived memories. Among these, the role of beliefs in the formation of self deserves special mention because beliefs are associated with the self network in varying degrees. There are beliefs that are widely shared in a community or society, along with ones acknowledged universally as valid or justified. These inter-subjective beliefs are only partially associated with emotions and are open to revision under the impact of evidence of various kinds while, on the other hand, there are beliefs of a deeply and intimately personal nature - ones that are held together by emotions and are not open to revision [31]. These beliefs are jealously guarded by an individual even in the face of strongly adverse evidence, and are revised 
only exceptionally — and that too often by strange and contrary means.

The self is involved in acts of cognition primarily through such beliefs of diverse types. A large part of cognition is directed towards the world 'out there' where neural excitation patterns generated by means of signals received from the world are processed with reference to the existing framework of stored knowledge, memories, and beliefs. Since cognition has to interpret the external reality with some degree of effectiveness, it does not primarily make use of beliefs deeply entrenched in the self-network. However, in the process of putting together the interpretation, the mind is often confronted with the necessity to make a guess since the store of knowledge and the inter-subjective beliefs, along with recalled memories and available concepts turn out to be insufficient in forming a conclusion that proves effective and adequate to meet the current cognitive challenge. What I have suggested in [26] is that, in such an impasse, the reasoning mind falls back upon beliefs of a more dubious nature, including the ones entangled with the self by means of emotions and unconscious drives - these now act as a prop that help the reasoning mind to leap across a logical gap. Once the impasse is broken and the gap is crossed, the cognitive process proceeds along new directions where a larger expanse of the conceptual space (the totality of concepts held in the mind) is explored and, perhaps, an effective conclusion is eventually arrived at.

This is how it seems likely that the self gets involved in a cognitive act of making an inference, especially one of an inductive nature. In a manner of speaking, what one comes across here is the cognitive face of self. The most remarkable expression of this cognitive face of self is to be found in acts of scientific hypothesis making where the hypothesis wells up, so to speak, from within the innermost self of the scientist.

The other face of self is predominantly emotion-driven, where cognition is not the primary concern. On a Sunday morning, my adolescent son urges me to take him to a western movie that all his friends have recommended highly, while my wife seems adamant that we should go shopping. As I finally give in to my son's request, it is my emotional self that makes me do so, and it would have been be the same emotional self that would be responsible if I were to choose the other option of pleasing my wife, 
though the emotions would work differently then.

In reality, the two 'faces' I refer to are only two ends of a spectrum, where cognition and emotion are mixed up in various manners, and the resulting variety is truly of an immense span since there are so many types of cognition and yet many more mixes of emotion. I will now say a few more words on the matter of "choice between alternatives' with reference to this spectrum involving cognition and emotion before I engage in further elaborations on free will.

\section{Inferring and willing: more on the cognitive and emotion-laden as- pects of self}

This is not to suggest that the mind has two distinct compartments, one for selfresources and the other for non-self ones. Drives, desires, emotions and the associated feelings, along with the set of idiosyncratic beliefs of an individual - all these taken together typically make up the self-network. Almost everybody has sexual desire and drive - the mere possession of the sexual drive has nothing to do with self. But the way an individual feels about sex, is roused by it, the emotions one goes through in sexual acts in diverse circumstances - all this is certainly dependent on his or her self.

In particular, the emotions, as I see it, constitute the single most distinctive component of self. Memories, beliefs and experiences of a person are more often than not tinged in some way or other with some mix of emotion and its associated feelings. And, that constitutes the involvement of the self-network with the memories, beliefs, and experiences. In a manner of speaking, emotions constitute the core of self. As indicated above, a number of beliefs under the protective wing of emotions get hooked up with the self-network while other beliefs, of a more inter-subjective nature, become associated somewhat more marginally. In a later section in this essay, we will come to examine the nature of emotions a bit more closely (click here to see). For now, I turn to the role of the psychological value-network. 
The value-network (commonly referred to as the reward network or reward-and-punishment network by neuroscientists) is based on a neural assembly of major relevance, with great - I may as well say all-pervasive - psychological significance. It serves the purpose of tagging a positive or negative reward-value to every experience so that when the experience is stored as memory, it gets stored with the value tag associated with it. The value tag is part of the emotional association with a recalled memory or a current experience and acts as a psychological guiding mechanism in decision making, planning, and preference-setting.

A decision or a choice requires a selection from among alternatives where the latter are of a disparate nature. From the point of view of strict logic, one cannot compare and choose between disparate alternatives unless these are somehow reduced to a common denominator. In the sphere of economic exchange, the common denominator is provided by money price, and theories abound as to how money price comes to play this role of the common denominator. One of these is the 'labor theory of value' and another, complementary, theory is the so-called 'utility theory'.

The psychological value-system provides one with the common denominator in terms of which choices are made between disparate alternatives in acts of inference. The imperative of a common denominator in the matter of a decision or a choice between disparate items was discussed in [26], chapter 4, where I pointed out that the question of choice comes up in the course of an inference when widely accepted rules (or principles) do not lead one to a unique conclusion.

Suppose you are engaged in the task of adding up four numbers. Here the universally accepted rules of arithmetic lead you to a unique answer, and the question of alternatives does not arise. Suppose, on the other hand, that you, as the judge in an essay competition, find two essays far surpassing the others in quality. Up to this point in your job as the judge, you followed widely accepted rules of literary judgment such as counting the number of grammatical errors, spelling mistakes, wrong usages, and such like, where these rules proved sufficient in discarding most of the scripts as undeserving of the highest rank. It was smooth sailing so far because the question of alternatives 
did not bother you. But now you find yourself in a fix since the same principles you have followed so far tell you that the remaining two students cannot be differentiated by these standard ones. You then invoke non-standard principles, perhaps not shared by most of your colleagues. Perhaps one of the two students has made copious references to a novelist you admire, indicating that she (the student) has read her (the novelist's) works widely and sensitively. While the other essay may also be indicative of a wide and high quality scholarship, your own bias (bias, that is, in the present context of getting the essays judged) tilts the scale in favor of the former of the two students. You thus make use of a dubious principle of judgment, perhaps not too consciously, when other more sound and widely accepted principles failed to let you come to a unique conclusion. What helps you make the final choice is a standard of valuation which, though questionable as a principle, lets you choose between disparate alternatives that could not otherwise be reduced to a common denominator. In other words, in this idiosyncratic act of literary valuation, it is your psychological value-system that guides you in your decision-making.

Similarly, and more generally, widely shared and inter-subjective beliefs may prove to be inadequate in leading one to a unique conclusion in an act of inductive inference.

In keeping with what has been mentioned earlier, the rules of judgment invoked either consciously or unconsciously in acts of inference are mostly in the form of beliefs - some relatively more inter-subjective in nature and others much less so, the latter being the ones tied to emotions. Beliefs of this latter type operate mostly at an unconscious level and are hooked up with the self-network of an individual.

What is more, the question of alternatives may not arise explicitly in many a case of inductive inference. In the course of making an inference, the transition between a phase of invoking a set of more widely accepted inter-subjective beliefs, and that of making use of emotion-laden idiosyncratic ones (because of the former set of beliefs proving to be inadequate) may be quite seamless, and the question of alternatives may not even arise in the mind of the individual making the inference. Such is likely to be the case when a housewife finds three items in a departmental store, all three she has 
sometime or other thought of procuring as useful ones for her household. As she comes out of the store having purchased only one of the three, her husband, in mentally reviewing her action, thinks that she somehow weighed the three options before her and finally 'chose' one of those. While this may be a correct description of the mental processes she has gone through it may, on the other hand, have been equally likely that her psychological value-system worked in tandem with whatever other standards of preference were active in her mind (in the form of beliefs about utilities of various household items) so as to help her arrive at her 'choice' without having to weigh between the options at any intermediate stage.

This is something that one has to bear in mind. To the extent that I distinguish between acts of inference and acts of willing, to that same extent I accept the possibility that, in one case, commonly accepted and shared standards of evaluation are made use of and more idiosyncratic standards are resorted to in the event of a toss-up between alternatives while, in the other case, the role of emotions aided by the psychological value-system leads to an internal or an external act in one single process without a transition between the two phases alluded to. However, like everything else in this world, actual mental process may involve a mix of these two types where alternatives are weighed only implicitly and unconsciously, depending on how exactly the various possible emotions get involved in the process. The psychological value-system always operates in association with emotions and works in strange ways. As a consequence, it may not be possible to clearly classify an action or thought as one associated with either inferring or willing because of our ignorance of the relative degrees of involvement of cognitive and emotion-based factors in the relevant psychological process.

This brings us back to the distinction between 'intrinsic' and 'extrinsic' rules of evaluation. The choice, if any, exercised in an act of willing, is determined by the beliefs and emotions intrinsic to the individual engaged in making the choice, and may have little to do with how the same psychological act appears to some other individual whose appraisal is more often than not based on a distinct set of extrinsic rules. The alternatives from among which the choice appears to be made may, on the other hand, be more of a matter related to extrinsic standards. This, for instance, is the case of the husband 
who finds that his wife purchases only one among three items in spite of her liking, expressed on earlier occasions, for all three of those. To the husband, the wife performs an act of choice from among alternatives where the choice appears to be a 'free' one, since nothing seems to favor one of the items over the other two by his standard of reasoning. What he is not aware of is, of course, the immensely rich and complex psychological resources belonging to the self of his wife that operate in their own strange way.

In summary, the 'self begins precisely where all commonly shared extrinsic rules, standards, and beliefs cease to be operative. What appears to be a psychological act of 'free' choice may actually be a strange and complex process dominated by the interplay - partly conscious and mostly unconscious - of emotions and psychological valuations.

The rich complexity of all the intrinsic mental resources is gradually being appreciated with gathering evidence from studies in neuropsychology and other related areas of investigation (see, for instance, [22], [24], [2]). Speaking for myself, I am aware of only an insignificant part of the stupendous volume of concrete findings in these areas of study, and that too only vaguely and indistinctly. Still, I don't feel like I'm sticking my neck out too perilously when I suggest (along with other 'determinists') that acts of 'free' will are determined in strange ways by the intrinsic mental resources of an individual and are free only from the point of view of commonly shared beliefs and standards of appraisal.

I am reluctant to get myself embroiled with the issue of 'determinism'. But reluctant or not, the issue keeps cropping up in any discourse on free will. It is, however, one of the more difficult things to get a handle on while examining as complex a system as the human mind. As I have indicated in an earlier section, I share the view that all psychological processes are anchored in events of a predominantly electrochemical nature taking place in the brain (as also in the body [32]; see also [8], chapter 4, for background) and it is in this sense that the exercise of will (as also an act of inductive inference) is 'determined'. However, just saying that something is determined by some other thing does not help us much if that other thing is a complex system whose 
operations are not determinable. Asserting that some event is determined is not the same thing as saying that it is determinable as to how exactly it is determined. In this essay we will have some more to say on this muddled issue of determinism. For now, I suggest that a better - and less confusing - way of saying that an act of willing is compatible with determinism (it certainly is, if one insists on using the term 'determinism' in an all-pervasive sense, in which case it amounts to little more than a declaration of faith) is to assert that it has causal antecedents. Of this, more later.

The issue of determinism versus free will appears, in the context of this essay, to be one of not too much of concern for us, though it certainly needs be clarified to the extent possible. I now collect all the observations made in paragraphs above to state the following summary:

Imagine an act $\mathrm{X}$ to be performed by a person $\mathrm{A}$ in some external context $\mathrm{P}$, where we assume that a sufficiently large number of factors relevant to the act $\mathrm{X}$ have been included in specifying the external context (this is a problematic assumption, but let us grant it for the sake of clarity). Imagine now that other individuals $\mathrm{B}, \mathrm{C}, \ldots$ with a similar disposition as A are found, in the same context P, to perform, instead of the act $\mathrm{X}$, acts $\mathrm{Y}, \mathrm{Z}, \ldots$; ; a commonly accepted way of describing this variability is to say that, under the context $\mathrm{P}$, A chose to perform the act $\mathrm{X}$ from among the available alternatives $\mathrm{X}, \mathrm{Y}, \mathrm{Z}, \ldots$. . I do agree that it sounds grossly simplistic to summarize the commonly accepted description in this manner, but I'll clarify.

One needs be clear in one's mind as to what the term 'similar disposition' is intended to mean. What I mean by 'disposition' includes a common educational and cultural background. Now, let us be specific as to what is involved here. When we say that two persons have the same educational and cultural background, we really mean that they share the same knowledge base and the same set of shared memories and intersubjective beliefs. Where they differ, and differ spectacularly, relates to their selves. Here lies the crux of the matter, for which one has to refer to the internal context relating to an individual. As I have indicated earlier, the internal context is, in a manner of speaking, made up of two parts - a shared part, and a self-part. 
Speaking more precisely, the term 'context' is to be used with reference to some particular act of inference or exercise of will. I use the term in a slightly broader sense here with little possibility of confusion.

In other words, when I speak of the persons $\mathrm{B}, \mathrm{C}, \ldots$, having a common disposition as A, I actually refer to the shared part of the internal context of A herself. And when we speak of 'available alternatives' we actually mean the alternatives from the point of view of this shared world-view. In the context of an act of inference or an exercise of will by an individual, a shared world-view can lead to one of two situations - either it leads to a well-defined and unique position based on the shared memories, beliefs, and principles making up that world-view, or it ends up short where that individual fails to arrive at some particular inference or to make up her mind as to how exactly to exercise her will. Such, for instance, is the case of the literary judge finding herself in a fix when commonly followed literary standards of judgment are found to be of no help in deciding between two students (call them $\mathrm{X}$ and $\mathrm{Y}$ ) both of whom appear to be equally deserving of the first spot in the competition. If one imagines two different persons (call them A and B) in the position of the judge, then it is quite conceivable that $\mathrm{A}$ would find $\mathrm{X}$ to be superior while $\mathrm{B}$ would judge $\mathrm{Y}$ to be the more deserving of the two. This is precisely because the commonly shared standards of literary judgment prove to be insufficient and the two judges have to turn to principles specifically valued by themselves in breaking the impasse.

This example is admittedly a bit simplistic - standards of literary judgment are not so sharply classified as belonging or not belonging to a shared set of beliefs and principles; I have made use of it only to put forward the idea that the internal mental resources involved in acts of inference and of exercise of will can broadly be divided into two groups - one made up of commonly shared memories, beliefs, and principles, and the other specific to individuals. And, the various 'alternatives' that may be associated with the act are nothing but possibilities with reference to which the shared mental resources remain neutral and undecided. The choice is eventually made by individuals making use of psychological resources anchored in their respective selves. 
Having said this I must add that, while a choice may seem to have been made, it may not even feature in the actual mental processes of either of the two judges.

In the matter of making a distinction between shared and inter-subjective mental resources of an individual and the self-based psychological resources built around her repertoire of emotions, one can, in a manner of speaking, further describe the latter as comprising a spectrum, one end of which interfaces with the shared resources (memories, shared beliefs, knowledge base) while the other end is completely engulfed in emotions (the psychological self). I refer to these as the 'cognitive' and the 'emotionladen' faces of self. The cognitive face, made up of beliefs of a partly inter-personal nature, is, at the same time, hooked up with emotions that get involved in the making of an inductive inference. This, in brief, is how one can notionally describe the mental resources of an individual in the context of the present essay.

\section{Constraint and freedom}

When one speaks of 'free' will one actually means freedom from constraints. It needs to be appreciated that, significantly, the constraints are not those relating to mental processes groaning under deterministic shackle.

When a judge in a legal trial prepares to deliver her verdict, she feels heavily constrained, and she herself would be the first to concede that the constraint comes from the mass of evidence, the arguments put forward by the learned counsels, and the meticulously formulated clauses of the penal code, not to speak of the broader principles of jurisprudence and human justice. She is to refrain from basing her verdict on her personal beliefs and emotions as best as she can and has to go by the precisely drawn documents now piled up before her on her desk.

Contrast this with the preparations of the lawyer representing the accused in the case as the trial was about to begin. She was also constrained by a good number of things - by the clauses of the penal code, by her commitment to the accused, by her legal ethics, and so on. But she was a bit more free to make use of mental resources specific to her 
own self. She could, for instance, rely on her personal hunch to discard one prospective witness and ask a somewhat less reputable person to the witness box. What is more, she was, to begin with, free to make use of her reasoned considerations and her gut feelings based on her emotions even to deny her services to the client altogether. As the trial proceeds, everybody involved with it gets more and more constrained by the mounting evidence and arguments, and finally the judge finds herself before the mass of piled up documents heavily constraining her away from making use of her own personal feelings.

Of course, as in everything else in this world, constraint and freedom co-exist in real life, and neither of these two is to be found anywhere in pure form. The judge is more constrained (and less free) while drawing her verdict than the lawyer preparing for her defense of the accused, but even she is not absolutely constrained, simply because the mass of piled up evidence along with the clauses of the penal code and the principles of jurisprudence may not unequivocally lead to a verdict. There may still be some scope for interpretation where she can possibly invoke her own personal judgment to some marginal extent, which is why the case may eventually go to a higher court. Beginning from the time before the accused was committed to trial up to the settlement in the higher court, freedom of choice (in the context of the verdict) goes on getting reduced progressively.

A citizen is 'free' - unfortunately so - to indulge in drug abuse, a great deal of medical and social admonition notwithstanding, precisely because he ignores the latter and commits himself to his inner propensities. He can be said to have made a 'free' choice precisely because a second individual with similar background can possibly make an equally free choice of saying no to drugs. And the overriding fact is that, both are subject to the iron shackle of determinism, if that is how one chooses to describe the operations of a billion or so of neurons that make each of them do what he does.

Among two students of art college, one chooses a life of poverty and deprivation while committing himself to the practice of art as a means of human liberation. The other chooses to go in for commercial art in an ad agency so as to be reasonably certain of a life of affluence. Knowing that the two careers are possibly open to an art student 
and that some adopt one of these while some others adopt the other, it is commonly said that each of the students 'chooses' from among the two alternatives. In reality, however, there is no reason why the 'choice' of each of the students is anything but the outcome of a deterministic process based on neural interactions. The aspect of determinism eludes us because the workings of neural and psychological factors relating to the selves of individuals often go unacknowledged since these are hidden even from our own awareness.

In summary, once again, free will involves a 'free' choice only in the context of (and from the point of view of) inter-personal or universal standards of judgment while it is, at the same time, 'determined' by the operations of psychological resources hooked up to the self of an individual.

The rules of mathematical logic, along with the those of set theory are said to constitute a universally valid set of principles precisely because these are constructed so as to be independent of contingent standards of judgment. When a mathematician sets out to present the proof of a theorem she doesn't enjoy any leeway to deviate from these universally accepted rules. Likewise, the principles of evidence, the clauses of the carefully constructed penal code, and the principles of jurisprudence are supposed to constitute a similarly forbidding set of constraints within which a judge prepares her verdict in a trial. Even so, the rules of mathematics are more universal than those constraining a judge, precisely because the latter are designed to codify a set of principles relating to human behavior, while mathematics abstracts away from all contingent human factors.

Significantly, even mathematics is not as unrelenting as it is thought to be. There remain foundational questions in mathematics that tell us that no absolutely foolproof structure can ever be had in this world. Alternative approaches are possible within the world of mathematics concerning the interpretation of mathematical objects and mathematical truth (see, for instance, [14]).

No less significant is the fact that a mathematician in the process of discovering a mathematical theorem faces a completely different terrain as compared with her colleague 
who is preparing a proof of some other theorem for publication in a journal. Proof or justification is a matter distinct from discovery, because the latter is primarily an act of an individual in the capacity of her own self and is only ultimately one that is to conform to strictly laid down principles. Justification, on the other hand, is a process where, ideally, there is no leeway for the self to operate.

The process of discovery of a mathematical or scientific truth is referred to as one of abduction where a prospective theorem or scientific theory first appears as a conjecture and is then justified in terms of strictly laid down principles.

\section{Discovery and justification}

The context of discovery is commonly distinguished from the context of justification [41], where the former is given a wide berth in the philosophy of science on the ground that it belongs to the murky terrain of psychology. Justification, on the other hand, is supposed to be a 'logically' well-defined process where there are strict standards involved. While mathematical justification is indeed a highly regimented exercise, the same cannot be said of theories in natural science, where one has to depend on confirmation by experimental observations coupled with 'internal consistency'. However, observation itself is theory-laden and the evidence of consistency is also not of absolute reliability since consistency is judged by existing standards, these being once again tied to current theoretical perception. In the end, scientific theories, however strongly justified, constitute intelligent interpretations of certain cross-sections of reality [26], which is precisely why these undergo spectacular revisions from time to time on the strength of 'evidence'

from newly explored cross-sections of reality and of revisions in the existing modes of thought.

But this is not the place to point a critical finger to possible fault lines in the justification of theories in the sciences because, going by current standards of justification, a finished and successful theory can indeed be accepted as one that, at least provisionally, has vindicated itself. A theory is preceded by one or more conjectures or hypotheses that acquire the stature of a theory only when they have successfully passed through 
the rigorous process of justification. Justification is usually a social process where a community of scientists made up of one or more working groups examine the hypotheses with critical eyes.

While the process of justification follows some strictly formulated grammar, that of discovery, in comparison is, shrouded in mystery. In contrast to the process of justification, a conjecture is formed in the mind of an individual. Even so, a conjecture is not plucked out of thin air. There occurs a two-fold process within the psychological terrain of the individual that can be sketched in broad outline even as that terrain is too misty to allow us a clear vision.

What is significant about the process of discovery, i.e., the one of formation of a conjecture, is that it must involve some measure of justification during this very process itself. A conjecture is formed by a process of inductive inference, and is essentially in the nature of a guess. But it is, at the same time, an informed guess. A scientist makes good use of the huge repertoire of the knowledge base stored in her mind in her endeavor to arrive at a reasonably good conjecture. But that, in itself, is not enough for arriving at the conjecture - otherwise, any and every reasonably well-informed colleague of hers could come out with it.

Along with the knowledge base, the scientist also makes use of a enormously large repertoire of heuristics [26] stored in her mind, where a heuristic is a fragmentary belief, of the nature of half-formed knowledge or some rule of thumb that has earlier been found to be efficacious in arriving at some sound conclusion. A good chess player makes copious use of such heuristics in addition to the set of memorized chess moves previously analyzed and commented upon by experts. The heuristics in her mind are made of vaguely formulated and elusive patterns of moves that perhaps she herself cannot set down clearly in writing but ones that fleetingly circulate in her mind, unconsciously driving her on to make some surprisingly spectacular move in a difficult situation. She, of course, does not make use of these half-baked patterns of move without due deliberation - once a move comes up in her mind as a result of processes she is only vaguely aware of, she sizes it up by looking hard at the current position of the board and gauging 
its consequences several moves ahead. This is how discovery and justification go hand in hand in the mind of the individual engaged in the making of a hypothesis.

And, this is where a champion chess player differs from her lesser opponents. While an opponent may have an equal or even greater command of published chess literature, the champion enjoys a clear edge in the profusion of tacitly operating processes involving vague and elusive patterns of chess moves - ones set in motion by the current challenge on the chess board in front of her. These tacitly operating resources are the ones that can be said to be specifically her own that makes possible the one spectacular move that her opponent could not even imagine being challenged with.

Given a challenging situation on the chess-board, a good number of parallel chess games get played out within the unconscious mind of the champion in which the heuristics are made use of - ones in which a good number of moves are tried and discarded, with one surprise move selected at the end which she now examines critically in the context of the actual position on the board. This unconscious process of sifting and selection is what the psychological value-system is so good at. The value-system operates in assigning positive and negative valuations (in terms of vague feelings of satisfaction and discomfort) as the mind engages in parallel processes of counterfactual thinking (see [17] for the neuropsychology of counterfactual thinking).

As mentioned in earlier paragraphs, the psychological value-system involves the activity of specialized neural assemblies aided by a number of chemical secretions, and is of early evolutionary origin. It attaches a positive or a negative weight to the affects, emotions, and feelings associated with memories, thoughts, or perceptions of current events, and is an integral part of the self-network of an individual. We will have something more to say on this remarkable device later in this essay (click to see). For now, we note that it is the value-system that is responsible for the ability of the mind to sift through alternatives when shared or explicit principles fail to do the job. It is precisely this gap, where the knowledge base of an individual or her store of inter-subjective beliefs does not help her reach a well-formed decision, that her self-based resources come forward, with her personal beliefs, hooked on to her self-network by means of emotions, 
getting involved in the act of inference-making. These beliefs, along with the positive or negative weights brought to play by the value-system, help her weigh between alternatives in terms of a common denominator - a task where the more 'logical' of her beliefs may have failed her.

In summary, it is the set of self-based beliefs, emotions, and feelings that plays proxy to the reason of an individual helping her in making logical leaps in acts of inductive inference, in which the psychological value-system acts as an 'internal censor' ([26],[29]) in a continuing process of justification. Once the self-based psychological resources succeed in playing the role of a prop to her in crossing the void where her knowledge base and her shared world-view were found lacking, she once again invokes these more worthy and proven resources, now in more focused awareness, to check and test the tentative hypothesis formed in the earlier act of the logical leap. If she now finds it lacking she discards it and starts the entire process afresh, this time armed with the negative lesson of the earlier failure.

This is how the cognitive act of the making of a scientific hypothesis can possibly occur in the human mind. All along, the scientist keeps on exploring larger and larger parts of her conceptual space ([4], [13]) and making new combinations and transformations in the conceptual elements in that space so as to arrive at some novel concept around which the hypothesis is formed. The knowledge base, the shared world-view, and the self-based psychological resources, all these are made use of in effecting a transformation that may, at the end of the day, prove to be of great value in the subsequent stage of theory building.

What is true of a momentous act of hypothesis formation in scientific exploration, is also true, in essence, in more mundane acts of inductive inference where, once again, clues acquired and retained tacitly by an individual in earlier experience, coupled with the operation of the psychological value-system, may prove to be effective in the formation of an inductive guess, to be subsequently tested by a more reasoned approach, perhaps based on more solidly grounded evidence. This, for instance, is how a physician, on examining a patient, often arrives at a tentative diagnosis which she subsequently tries 
to confirm by means of pathological tests of various kinds.

In other words cognitive acts such as a simple one of inductive inference or the formation of a novel scientific hypothesis make use of knowledge base and a world-view shared by a community or society at large but, at the same time, draw from self-based personspecific resources including the all-important value-system that acts as an internal means of justification called into play even as the act of guessing or forming a conjecture is carried out in the mind. It is the value-system that is ultimately responsible for whatever choice the inferring mind adopts from among possible alternatives.

\section{The self-network}

The self, in all likelihood, is based on a complex network made up of neural aggregates distributed over large regions of the brain, all interchanging coherent signals between themselves by means of synchronized waves moving across these regions where, additionally, direct interactions through neural pathways also take place.

As I have mentioned earlier, the fundamental point of view adopted in this essay is that psychological states and processes are all based on large scale neural aggregates where the functioning of any one of these aggregates relates, in turn, to the mutual interaction of a large number of neurons. The individual neurons in the brain operate in a more or less similar manner, but the aggregates differ greatly in the way they operate, being responsible for the fantastic diversity and subtlety of psychological states and processes. A single neuron in a functioning aggregate may die out, but the aggregate keeps on working.

In a manner of speaking, psychological states and processes can be looked upon as emergent qualities resulting from neural ones. One can look at the former (the psychological) as an epiphenomenon or a phenomenal appearance emerging from the latter (the neural). In the end, however, all these different labels are just so many ways of describing a supremely complex relation between what can once again be conveniently described as two 'levels of reality'. Labels such as 'emergent quality' or 'epiphenomenon' 
help our mind to somehow latch on to this infinitely nuanced and intricate relation - each of us interpreting the labels in his or her own way.

For the purpose of this essay, I focus on the following components of the self-network: (A) beliefs, (B) affects, emotions and feelings, and (C) the value-network. I'll now take these up one at a time. Added to these, a host of other components of major significance, such as personal memory (which is emotion-laden, see below), drives, desires, fantasies, fixations, and attitudes make up the entire self-network.

Among all these psychological components of the self, the vastly distributed web of beliefs of an individual is, perhaps, of an exceptional nature in that these may command a distributed collection of large scale networks in the brain rather than one or a few neural aggregates, since beliefs have a widely spread interaction with a large number of modules in the mind [7].

The self-network: personal beliefs

As Bertrand Russell observed, beliefs constitute "the central problem in the analysis of mind" (quoted in [42]). On the other hand, "Belief is one of the most commonly used, yet consistently unexplained, terms in neuroscience" ([25], preface).

The neural mechanisms underlying beliefs of numerous descriptions have been explored from a diversity of angles in [25].

Every individual carries in her mind an all-pervasive web of beliefs. Beliefs constitute the map by which she navigates the complex and uncertain world she finds herself in [1], and it is her web of beliefs that, in a sense, makes up her world-view. Belief has been contrasted with knowledge, and a comparison between the two commonly leads to the former being underrated as constituting a misguiding and unreliable psychological resource. However, as I have indicated above (see [26]), the two are continuous with each other, with a strange dynamics going on between the two both in a person's inner 
world and in the world of mankind at large. Caught between the two, truth suffers a precarious existence.

"Minds did not evolve to evaluate what is the truth. Our minds were equipped through evolution with an impulsion to create, transmit, and defend beliefs that have utility, whether true or not”. [42]

Among all the diverse beliefs of an individual, the ones most characteristic of her are those that are hooked to her self-network, simply because these are her very own, which she would not let go. That woman harbors a secret grudge against me and is out to destroy my family; I must be on my guard when I cross paths with her- this is a privately held belief that may or may not be true, but is a forceful one nonetheless. Personal beliefs like this constitute an individual's identity and an important component of her world-view (the other major component of which is made-up of beliefs of an interpersonal nature), and are strengthened and protected by emotions. "The most important observation - that emotion and cognition meet in beliefs and that this rendezvous is necessary for rationality - permits analysts to rethink concepts such as credibility and to better understand emotion's influence" [31]. It is common observation, for instance, that political beliefs - largely of a personal nature - are not always based on evidence and consistent logic, still, “... political belief systems modulate neural activity by facilitating the interplay between implicit emotional and explicit cognitive processes" ( [25], preface).

In other words, the personal beliefs of an individual have a dual role to play: on the one hand, these connect with the inter-personal beliefs that constitute a major part of her shared world-view and help her mental processes going in the guessing game of inductive inference while, on the other, these operate in tandem with her emotions and her neural reward-punishment system, making her exercise her free will.

A middle-aged lady, Ms A, out shopping in the marketplace, feels like having a cup of coffee and finds two coffee bars side by side. She observes a distant relative, Ms B, enter one of these, which sets her emotions soaring. She is loath to cross paths with Ms 
$\mathrm{B}$, believing in some hidden depth of her mind that she (Ms B, that is,) holds a secret grudge against her. Ms A 'chooses' to visit the other coffee bar for a relaxed cup of coffee without, perhaps, being fully aware of the cause of her momentary impulse. This is an instance of exercise of free will where a privately held belief of an individual guides her to an action in which she appears to make a choice where a second person in her place could well have chosen to act otherwise in virtue of her self-network operating along different lines.

It is in this sense that inductive inference and free will can be said to emerge from the same habitat offered by the self of a person, through two different exits, as it were, - the former as a cognitive act and latter as an emotion-laden and psychologically driven one. And it is because of this that the same act can often have a dual identity where the two faces of self join hands.

The self-network: emotions

Emotions hold the key to the self of a person. What is more, emotions are based on affects, the latter being the product of a neural mechanism of early evolutionary origin. Affects serve the important purpose of providing us with a primary and basic classification of objects, events, and situations of this world. They classify our universe into compartments, often overlapping with one another. There is, for instance, the affect of fear and terror - when turned on it initiates notable bodily changes and leads us on to flight. The affect is thus a mechanism that greatly magnifies a signal and leads to the generation of an innate reaction. And, at the same time, it initiates a set of emotions as well. The experience that turns on the affect, is then stored in memory with an emotional tag. The next time the memory is recalled, similar emotions are produced as if on cue, and once again one experiences a feeling of terror or fear, this time an endogenous one.

Though of early evolutionary origin, the affect system has a central role to play. It classifies the universe of an individual into a few basic categories, and thereby has a great 
adaptive value. While affects are innate and classify the universe of an individual into a few broad basic categories, emotions are psychological resources that keep getting enriched during the entire lifetime of that individual, making possible an exquisitely complex and fine-tuned classification of her universe with little participation of her conscious intent.

An exhaustive discussion on the affect system is to be found in [32] who bases his work on the pioneering work of Silvan Tomkins. Nathanson focuses especially on the affects shame and pride, the former having a negative valence and the latter positive, and describes how the self is built around the axis provided by these two. For an outline of Tomkins' affect theory, see [40]. The theory of the complex system of affects and emotions was initiated, among others, by Darwin.

In adult humans, the innate affect mechanism operates within a complex matrix of emotions and feelings, constituting the core of the latter. What is more, the core of the affect system itself is constituted by the value-network. This we will have a look at in the next section ( click to see).

Built around the core provided by the affect system, the emotions make up the major part of the self. Affects are inherited, but emotions keep on getting incorporated in a remarkably complex architecture throughout the developmental history of an individual. As mentioned earlier, our memories are colored with emotions, and every new experience, depending on the external and internal context in which it happens, undergoes a classification exercise by the joint action of the value-system and the affect system, and is then associated with a host of other memories and emotions to be finally assigned an emotional tag that may be either pronounced or subdued, but is one with a rich texture. A memory is never a simple store of information. It is always associated with other memories and with a remarkable mix of emotions which we may not always be aware of (see, for instance, [8], chapter 6). 
The memory of a thatched house in a village I left behind long ago may not mean much in itself and may not evoke a lot of emotions. But the memory of a village girl who lived in that house and joined me in childhood pranks in those bygone days, brought alive by the sight of a composed middle-aged lady I never expected to meet again, is more likely to raise emotions and feelings that not even the greatest literary talent can describe with any degree of completeness. The event of accidental meeting with the lady under completely different circumstances propels me into strange behavior that my wife fails to comprehend.

My impulsive behavior on meeting a lady I never expected to see again in my life is an instance of a hugely significant function of emotions that lends a stupendous complexity to the psychological life of a person and that often goes unnoticed - besides being responsible for a most remarkable classification scheme of memories and events from the point of view of the self of an individual, emotions provide an amplifying mechanism in a person's mental world.

Processes of classification and amplification go hand in hand. On reading casually a short story by an unknown author, certain memories are evoked in my mind by the action of my emotional system where the emotions become active by association with certain allusions in the story. This is the result of the classification of memories tagged with emotions. And, simultaneously, something momentous happens. I am electrified into action and immediately rush to the telephone to call an old friend, inquiring about a common friend of ours who has been suffering from a disease, and plan a project of raising funds for that suffering friend.

Side by side with amplification, the obverse of inhibition or suppression is also of relevance. As I propose to my friend a scheme requiring a flurry of feverish activity, he calms me down by pointing out that unhindered enthusiasm will have a negative impact upon the ultimate aim of helping our sick friend. My initial impulse is thereby moderated and the two of us then draw up a plan that proves effective later on.

The action of emotions imparts the feature of instability to our mental world while, at the 
same time, providing for the opposite feature of stability as well - the former in virtue of an amplifying mechanism and the latter by means of a moderating or inhibiting action. Emotions come with positive and negative valence generated by the pleasure-aversion (or reward-punishment) network (also referred to as the value-network or value-system in the present essay in the context of psychological processes) of the brain around which the affect system is assembled.

More often than not the instability is only of a local nature because of aversive reactions coming into play that inject a stabilizing influence into the mental and psychological processes. But for the moderating influence of my friend (in the event of my urge to provide support to a common friend of ours), my initial feverish impulse would continue to grow into a major turmoil while, in reality, the action of the stabilizing factor causes the initial instability to remain localized in my mental world, and to be productive of desirable consequences. At times, however, the emotions get involved into a runaway situation with a major disintegration taking place within the mental life of a person. But that is a different story I wouldn't venture into..... .

This feature of amplifying and stabilizing effects of emotions operating in tandem gives rise to an infinite variety, complexity, and texture to psychological processes relating to the self of an individual. Emotions operate on all scales, from the most commonplace of our activities to ones of momentous consequence. And, the alteration between amplification and stabilization never ceases: we get roused to fervent unrest only to be moderated back to prudent poise - this is how a young student suddenly knows that he can now solve the problem set by his teacher and then settles down to actually solve it, and this is also what makes the great artist pick up his brush in haste so as to give form to the vision that has so suddenly sprung up in him, then feeling a strange peace of mind as the painting is done.

The realization that appears like a flash in the consciousness of the student or of the artist is like a bubble that rises from the depths of their unconscious self. All the psychological resources making up the self operate within the unconscious mind. Indeed, it appears that, as with the emotions and the other major psychological states, con- 
sciousness is also an epiphenomenon of sorts: consciousness is a state of the mind that waxes and wanes like the tides, though with much less predictability and with constant accompaniment of underlying processes we are never aware of. Looked at this way, the dichotomous view of unconscious versus the conscious mind appears to be a somewhat skewed one. The two terms are used to denote mental processes that we are or are not aware of, where awareness itself is a state of the mind.

The issue of consciousness in free will is relevant in the context of this essay in a way that will become apparent after some more explanation relating to determinism and causation, and will be taken up towards the end (click here to see).

Like all psychological states and processes, consciousness involves the synchronized interaction between neural aggregates, along with the action of specific molecules that bind to specific sites in activating specific groups of neurons ( [34], chapters I, II; [35]). These few lines of mine are, of course, of zero content in so far as the problem of consciousness is concerned, and is no more than inane triviality. However, the neuroscience of consciousness is not of direct concern in this essay (for background on the question of consciousness, see [39], [21]). I speak of neural correlates of psychological processes as providing a backdrop to the latter.

In summary, emotions are the major resources that make up the self of a person, responsible for the generation of an exquisitely colored catalog of all the events and experiences of one's entire life, at the same time imparting a stupendous variety and complexity to psychological processes by means of local instabilities produced by the action of the affect system in general and the pleasure-aversion network in particular.

\section{Self-network: the psychological value-system}

The exquisitely tuned and complex system of emotions is assembled around the affect system, while the affect system in turn has its fulcrum in what I have termed the psychological value-system, or the value-network at several places in this essay. 
The term 'network' denotes an assembly of neural aggregates communicating with one another through synchronized wavelike modes of interaction, where the activation of the assembly as a whole corresponds to some particular psychological process or phenomenon. Such an assembly, in turn, communicates with other assemblies in the brain, generating complex patterns of psychological activity that never ceases in our lifetime. When one speaks of a 'system' or a 'network', it has to be understood from the context as to whether one is referring to the neural or to the psychological domain.

The fundamental position I start from in this essay is that the latter is a phenomenal appearance resulting from the former. It is in this sense that one can speak of two 'levels' of description - the neural and the psychological. Strictly speaking, it carries no sense to say that there is a two-way 'interaction' between the two levels. Whatever interaction there is, occurs between the various neural aggregates and between various assemblies of such aggregates (not to forget the interactions between the individual neurons themselves). The description in terms of psychological processes is a way of referring to neural ones. At the same time, such a description is an indispensable one - there is no way one can forget about the psychological mode of description and talk only in terms of neural processes.

Here is an analogy. When we speak of a gas, we talk in terms of its volume, pressure, temperature, etc., - all these being ingredients in the thermodynamic description of the gas. Each of these thermodynamic parameters is correlated with the motions of the molecules making up the gas and their mutual interactions. All the thermodynamic, or macroscopic features of the gas are expressions of what goes on at the molecular level. At the same time, no physicist ever dreams of doing away with the thermodynamic description and speaking only in terms of molecules and their interactions. Physicists never cease in their attempts to explain macroscopic observations in microscopic terms, but that has got absolutely nothing in common with any imagined attempt at doing away with the macroscopic mode of description in favor of the microscopic one.

In the context of neural aggregates and their activity, the value-network is also variously 
referred to as the reward system, the reward-punishment system, the pleasure system, the pleasure-aversion system, and such like. It constitutes the very core of the affect system of an individual, and is the basic mechanism that assigns positive and negative valence to all her affects and emotions, thereby making up the one component of her self-system that is of singular relevance in her entire mental life.

The value-network (or the value-system; the term 'network' has a connotation in the domain of the neural description) gets expressed as the positive and negative valence of the basic affects that Tomkins identified [32]. Among these basic affects the most fundamental are the ones relating to pride (positive), self-esteem, and satisfaction on the one hand, and shame (negative), humiliation, or aversion on the other. These two affects provide the driving engine for the enormously complex operation of the self-network.

Damasio has traced the huge expanse of the terrain in our individual and social life covered by the operation of what he refers to as 'biological value':

"Biological value has influenced the evolution of brain structures, and in any brain it influences almost every step of brain operations. It is expressed as simply as in the release of chemical molecules related to reward and punishment, or as elaborately as in our social emotions and in sophisticated reasoning. Biological value naturally guides and colors, so to speak, almost everything that happens inside our very minded, very conscious brains" [8].

In an almost epiphanic vision, Damasio has linked the activity of the quaint little neural assembly lodged in the brain with the course of human history itself. The neural pleasure-aversion system that modulates the development of the self, is itself modulated by the complex social interactions of men. Of archaic evolutionary origin, its services are co-opted, as it were, by all the other sophisticated networks of more recent vintage by means of which the human mind expresses itself. It holds the key to reason, rationality, aesthetics and conscience, on the one hand, and to human aggression, power, passion, and lust on the other. All these constitute the terrain covered by the free will of men. Contrasted with the enormity, complexity, and diversity of the terrain, 
the value-network itself appears almost puny and prosaic.

I am in no position to dwell upon the neurology of the psychological value-system and can only vaguely indicate that the major neural aggregates constituting the valuenetwork are mostly situated in the so-called ventromedial prefrontal cortex of the brain (VMPFC in the jargon of the neuroscientist) and communicate with numerous subcortical neural hubs. Indeed, it is this value-network acting as the core of the affect system, that is to a great extent responsible in imparting emotion-laden meaning to all our experience, all our memory, and all our vision of the future (the neural basis of the value-system has been outlined in [38]; [24] gives an exhaustive overview of the subject, including a large number of associated issues of major relevance).

Mechanisms generating pleasure and aversion are of evolutionary origin, and have a great role to play in the survival and well-being of individuals, communities, as also of species. To start with, these appear in the form of recognition and preference for sensory inputs having a direct role in the maintenance and improvement of bodily functions of the individual, in the well-being of communities, and in the propagation of the species. These include a host of inputs from various bodily organs of an individual and, perhaps more significantly, inputs from individuals in direct communication (the baby and her mother, the child and her peers, the young man and his beloved). However, the brain is a great classifier, mostly by the action of emotions and, in the course of development of an individual, learns to assign positive and negative value to whatever comes its way, the most effective means for this being social and cultural in nature.

Even the biggest supercomputer cannot faithfully store the myriads of small and subtle associations detected and made use of by the emotional system in the lifetime of an individual by means of which the psychological value-system assigns a positive or negative valence to every object of experience, every event, and every memory that form the universe of that individual. We feel pleasure and aversion consciously as also in the form of implicit and unconscious driving factors that affect our behavior.

Significantly, pleasure and aversion result from the activity of specific groups of molecules 
in the brain [24]. For instance, dopamine, a neurotransmitter of major importance is responsible in a big way for the regulation of desire, mood, and motivation [27], and the value-system depends crucially on the dopamine pathway in the brain. Another class of molecules are the endogenous opioids (enkephalins, dynorphin, endorphins) that are responsible for inhibiting pain and promoting pleasure. A third group of molecules consist of the endogenous cannabinoids that produce similarly rewarding sensations. Similar groups of molecules administered to an individual from outside produce a wide diversity of positive and negative effects, generating a vast and complex range of medical, social, legal, and ethical issues having far-reaching consequences for mankind.

Within the limited scope of this essay, the major relevance of the reward-punishment system relates to its role in decision making, where one has to consider two dimensions of it - one in the conscious domain and the other in unconscious psychological processes.

It is commonly accepted that decisions are made by the exercise of rationality where a person is aware of the reason she is making a choice from among several alternatives. A traveling salesman learns from a guidebook that there are two possible routes to his next destination, one of the two longer than the other by hundred-odd kilometers. He chooses the shorter route by invoking the 'rule' of least distance to travel and least time in consequence, which is a widely accepted one. However, on second thought he changed his mind because the available bus service through the shorter route would land him at his destination at an odd hour in the night which would be a bothersome inconvenience. Once again, the salesman is in good command of his senses and is rational in adopting the altered decision. At times, however, decisions are taken without conscious attention being directed to the task, where unconscious psychological factors play their role. In both cases, though, the psychological value-network plays its seminal role in making possible the decision arrived at.

Unconscious decision-making has drawn the attention and interest of psychologists and neuroscientists in a big way in recent years ( [9], [10], [43]; see [33] for a critical review). As mentioned above, it would be prudent to avoid a dichotomous conscious-versus- 
unconscious point of view and to focus on psychological processes that an individual is not aware of when making a decision, even in the case of decisions made consciously. What one needs to distinguish between is the nature and extent of participation of unconscious processes: whether self-linked resources are brought to bear in the matter of choosing between options or whether widely accepted and recognized principles (aided by the activity of the value-network) prove adequate in making the choice.

It appears likely that the former of the two possibilities mentioned above is of common occurrence, especially when the choice requires an evaluation along multiple dimensions, each with its own criterion (see, e.g., [11]). Conscious and rational decision making is, of course, important in situations requiring a high level of integration and comparative analysis of possible consequences of making various possible choices. However, as found in numerous studies relating to the so-called 'rationality debate' (see, e.g., [28], [44]; see [26] for a brief outline), choices and decisions in real life are often adopted in substantial discordance with norms of rationality. There exists a growing body of literature on the role of the value-network (commonly referred to as the reward system) in decision-making under various circumstances ( [38], [24], [45], [2]). The value-system plays the role of the arbiter in conflict resolution, which is of central relevance indecisionmaking.

\section{Complex systems: determinism and causation}

\section{Complex systems: a brief overview}

The self-network is a complex system. Here the term 'complex' needs some explanation. We often use this term in a commonsense manner of speaking to indicate that something (i.e., some entity or phenomenon under consideration) defies a satisfactory understanding in virtue of too many factors being involved in it that cannot be simplified in an obvious way. For instance, it may be difficult to explain the behavior of a system in simple terms, say, by means of a small number of mathematical equations whose solution then can be interpreted as constituting the explanation sought for. In the field of mechanics, a point particle moving in a gravitational field, or a simple pendulum, 
constitutes such a simple system.

In this present essay of mine, I will not depart too much from such a commonsense interpretation of the term 'complexity', though the term has a precise and rigorously defined meaning in the field of computational science. However, the technical definition of the term is not totally unconnected with the commonsense understanding, and I will adopt an interpretation that is, in a manner of speaking, midway between the two while, in this, I will have in mind something called 'dynamical complexity' which has its link with 'algorithmic complexity' of computational theory.

Imagine, then, a system whose behavior we want to describe or explain. The 'system' in question may be the human brain, a tribal community, or a group of school children assembled in a class-room, or even a set of differential equations in mathematics telling us how a number of particles move about under mutual interactions. Imagine further that we have some language in which we can record its behavior in as much of details as possible, though it may take up an inordinately long time and an inordinately large space (a huge bank of computer memory, for instance) to actually assemble that record. The behavior, moreover keeps evolving in time and the record will have to be kept open for future addition of data.

Now, in everyday practice as also in science, we look for compressed descriptions of how a process actually unfolds or is expected to unfold. Such a compressed description - made up of instructions, rules, or statements - that suffices to tell us how the process or behavior unfolds without having to go through the voluminous and detailed records of the behavior itself is referred to as an 'algorithm'. For instance, the 'rules of multiplication' constitute an algorithm of how a multiplication of any two numbers is to be done.

Referring to the behavior of a number of mutually interacting particles, one may argue that Newton's equations of motion constitute the algorithm for describing this behavior. However, in numerous cases of interest, the equations do not count as an effective algorithm. Given the positions and velocities at some initial time to within some specified 
accuracy, the equations prove useful only up to some finite time interval because the error in the predictions obtained from the equations increases with frightening rapidity (referred in mathematical terms as as an exponential growth). It does not help to increase the accuracy in specifying the initial conditions since, however small the inaccuracy in the specification of the initial positions and velocities of the particles, the error in the predicted state of motion at some future time grows with overwhelming rapidity. Suppose that one has observed the states of motion at small intervals of time for a long series of observations and wants to compress the information so obtained into a set of statements making up an algorithm. Instances abound where the algorithm achieves little compression if at all, because of the exponential growth of error of prediction with time and with the inaccuracy of specifying the initial conditions of motion. This is referred to in mathematical and scientific literature as 'sensitive dependence on initial conditions'.

The dynamical behavior of three or more particles whose interaction is given by Newton's law of gravitation is a case in point since it is stamped with the same sensitive dependence on initial conditions that I have mentioned above. The fact that, the aforementioned sensitive dependence notwithstanding, planetary motions can be predicted with such splendid accuracy, is a consequence of the very large mass of the sun as compared to the planets, making use of which there have been devised extremely accurate computational schemes that beat the exponential growth of error of prediction up to very long times indeed.

In the so-called three-body problem of mechanics, as in many other problems, the sensitive dependence holds for certain sets of initial conditions while, for other initial conditions, the behavior turns out to be less 'complex'.

The sensitive dependence on initial conditions is indicative of some amplification mechanisms inherent in the mode of interaction of the components of the system that one is trying to understand and describe. However, an unfettered amplification leads to devastation and causes a system to implode. This is what happens sometimes in an atmospheric system (especially when coupled with an oceanic system) in which a large 
number of amplifying and stabilizing factors operate simultaneously in some kind of uneasy truce but once too often the amplifying factors get the upper hand resulting, perhaps, in a tornado or a hurricane.

More often than not, a complex system is made up of a 'large' number of constituent subsystems (see [18], [47] for background) in mutual interaction where the term 'large' depends on the context. There exist model mathematical systems where only a few variables exhibit dynamically complex behavior. But when one tries to see how those model systems assume relevance in real life one often finds that the few variables defining the mathematical model only superficially describe the system under consideration, and there exist underlying phenomena, involving other 'players in the drama' that have their role in generating the complexity.

For instance, you are, perhaps, interested in the epidemiology of a pandemic raging through large territories over the globe and, with a group of colleagues, are frantically trying to predict how and when the pandemic is expected to subside. Looking over the data covering a few weeks, you have a feeling that you have hit upon the right 'model', only to be plunged into despair a week or so later. The system you are trying to describe is only superficially made up of the numbers spewed out of your data bank. You quickly discover that your 'system' involves a lot of factors like government policies, human migrations, community culture and psychology, economic factors, food distribution systems, health support systems, and so on, and, finally, the behavior pattern of virus strains - their intriguing manner of invading various hosts and undergoing mutations - as also the enormously complex immunity systems of individuals. Do I deliberately make things too complex here? Maybe or maybe not. You can publish research papers by focusing on this or that particular aspect of the problem and your paper may be cited a good number of times, but still your prediction about the time series of progression of the pandemic as a whole is likely to go wrong in a major way every once in a while, when this or that underlying factor makes its presence felt.

The mother of all complex systems is, of course, the world at large - Nature itself (or, herself, if you like). And, competing with the complexity of the universe there is 
- human nature. The latter is only a part of the former, but is no less complex when considered within its own domain. And this brings us to one more intriguing facet of complexity - complexity occurs on all scales or, put differently, at all levels.

Complexity, in other words, is layered. When we try to understand or explain the behavior of a system (call it A), we look at it within some context. Looked at from a different perspective, one is likely to discover a substratum (call it B) that constrains the behavior of the system A we were looking at. As we discover that the behavior of A occurs in the backdrop of the substratum B, the properties or patterns describing A may appear as emergent from those of B. The enormously complex turbulent flow of a fluid may be looked upon as an emergent behavior from underlying stresses and strains between small volumes of the fluid that generate wavelike motions in it while the stresses and strains between the small volume elements themselves may be described as emergent from electromagnetic and quantum mechanical interactions between the molecules of the fluid.

This is a good place to summarize. Complexity is ubiquitous, it is generated by interactions among a large number of components of a system, these interactions involve a dynamic interplay between amplifying and stabilizing factors, and complexity is layered, giving rise to emergent patterns of behavior.

Among these, I should like to refer again to the fact that interactions in a complex system involve amplifying and stabilizing factors in interplay, and the associated sensitiveness to initial conditions. There is a little bit of mathematics in it (when simplified and condensed in the context of the present essay). The aspect of sensitiveness to initial conditions is, in a sense, just another name of the aspect of amplification - the interactions tend to amplify an error, howsoever small, in the specification of the initial condition of the system. But as I said, amplification cannot be the whole story. Amplification implies some kind of destabilization - it tends to disrupt a pattern of behavior, generating some new pattern. A quiet phase of atmospheric stability is suddenly broken by a hurricane. But the atmosphere is a huge system - the hurricane does not destabilize the atmospheric condition of the entire globe all at once - interactions brought to 
bear by surrounding atmospheric systems cause things to subside. A few weeks later, a hurricane breaks out someplace else...... .

In mathematical jargon, the sensitiveness to initial conditions and the factors leading to stabilization of the system as whole, are expression of the non-linearity of the interactions among its constituent parts. From a broad point of view, non-linearity is ubiquitous in real-life systems precisely because the interactions commonly involve a large number of components and, what is no less significant, because the components themselves are complex systems.

The stabilization of behavior in a complex system preventing global disruption in it following amplification and local destabilization is, in some contexts, referred to as the capacity of 'self-repair', associated with the feature of 'redundancy' (a flaw developing in a process does not make the system collapse). For instance, the human body has an amazing capacity of this kind. In biological systems, this capacity is, of course, the product of a prolonged process of evolution. More generally, however, the profusion of interactions of various kinds among a large number of components of a complex system is likely to generate stabilizing factors that sustain the system as a whole. The geological system may be cited as a case in point. Stupendous natural upheavals notwithstanding, the geological system may be described as a globally stable one - of course, within a long but limited time horizon.

\section{Determinism and causation}

Determinism is too big a thing as far as I am concerned. It is interpreted in diverse ways by diverse groups of people. A common interpretation of it asserts that, given the state of the universe at any instant of time, its state at any later time is completely determined. Others add a new strand to the story and assert that, given a complete knowledge of the state of the universe at some given instant, and of the laws of nature, its state at any future time can be completely predicted.

All this involves too many concepts of humongous proportions - the universe ..... the 
state of the universe .... completely determined .... complete knowledge of the state laws of nature complete prediction all this makes the head spin.

But I will pick out one strand in this divergence and profusion of points of view regarding determinism that I find relevant for my purpose here - according to one point of view, determinism is something inherent in this universe regardless of how we come to know about it, of what we know of its inner mechanisms, and of how much we can predict the course of things while, from the other point of view, it is precisely these things that determinism means. One point of view (the 'ontological') looks at the universe-in-itself and the other ('epistemological') at what we can know and how much we can tell. There is a view of science that tells us that the two are on a course of convergence. I am not so sure, but I'll let it go, because points of view cannot be fought over.

For our purpose here, I will not talk of the universe. I will not talk of laws of nature either, since these are too big things as far as I am concerned. Instead, I would rather focus on one single system such as, say, the human mind - the mind of one single person. I would not talk of how much of the thoughts and actions of an individual is determined by the state of the universe in some remote past, nor of how much can be told of those thoughts and actions from the standard model of elementary particles or some updated version of it. I would rather focus on how the mind operates - how the known facts about the working mechanisms of the human mind can be said to cause and determine the thoughts and actions of an individual at some particular point of time, in given surroundings and circumstances. But even this is a vast and fathomless question.

Take the external context first. Countless signals of various descriptions originating from external objects and human beings ceaselessly impinge on our senses and we pick up and store countless other signals by our cameras, our telescopes, and our laboratory equipment. All these signals, carrying information of some kind or other, can be said to constitute a truly infinite multitude. Are all these signals recorded, registered and processed in the mind? Of course, not. The mind selects out a fraction of these. It processes the information, responds to the results of this processing, stores some of the 
results, assesses some others in association with information processed and stored in the past, evaluates what it finds and, all the while, keeps on receiving and integrating incoming information from the world out there.

Take just the first step in this entire process of amazing complexity. On what does the selection of information depend? Me and my friend are walking one evening in a garden. My mind picks up the peculiar fragrance of a wild flower and suddenly goes back some twenty years... . My friend, on the other hand, notices the gathering dark clouds and urges me to return home. We pick up some information consciously, and a vast amount of other information (other 'signals', if you like) without being aware of those, and all this depends in a hugely complex manner on our memories and our current state of the mind. Our registering of the signals into sensations and perceptions, our recording of those into memory, our response to those in the form of thoughts and actions, all are results of an intricate processing and interpretation, in which the processing and interpretation depends on emotion-laden memories, beliefs, and value-assessment based on the reward-punishment system where innumerable little inferences and decisions are made implicitly.

In the midst of all this bewildering complexity, what 'determines' our thoughts and actions? To be sure, thoughts and actions do not emerge from thin air. They have causal antecedents. But these antecedents constitute a tangled heap. We can try to painstakingly trace out and disentangle these, assessing the role of this causal factor and that. And that, exactly, is what is being done by neuroscientists, psychologists, physiologists and a host of other people dedicated to their respective fields of inquiry in which, above all, commonsense understanding and commonsense theorizing of unassuming, ordinary folk of this world - people with no specialized training whatsoever to speak of — contributes hugely (and, implicitly).

It may well be said that every thought and action is ultimately determined by the state of the universe in some remote past. Me or nobody else can meaningfully contest that stupendously weighty assertion. But it is quite a different matter to say that every thought and every action has causal links with processes in the human brain along 
with a host of associated processes in the body at large, and with signals received and picked up from objects and people in the environment, and to assess the relative roles and weights of all these concrete causal factors - how all these factors come together and realize the thought or the action under consideration. For every single event in this world a number of causal factors come together and make it happen. And, out of the association of all these causal factors, not one but a number of other events or their causal antecedents are generated. The causal chains in this world of ours are not independent ones running in parallel with a neat and unique cause-effect concatenation along each of these parallel courses, but are impossibly interlinked with one another where several results are generated at a time from several causes working together; but it still makes sense to look at the cause-effect relations, to assess the relative roles and weights of the multifarious causes behind an event, and to identify major and minor causes while at the same time appreciating the context and the sense in which these can be so identified - it is so often the case that causal factors that can be ignored in one context become vitally relevant in another. It is indeed a difficult and back-breaking game - working with complex systems.

As I said at the very beginning of this essay - you may have forgotten it under the veritable outpouring that has followed since - all mental activity occurring under given circumstances, including those that can be described as psychological, are based on and are caused by neural processes, where the latter are electrochemical in nature, and are associated with a host of other physiological processes. Among all such processes, I focus on the activities of the self-network. Because it is the self-network and its dynamic interaction with other neural assemblies that appears as the causal link for many an exercise of free will - free will being 'free' precisely because it is not constrained by shared world-view and is exercised differently by different individuals. Since the largely invisible self-network and the various interactions originating in it play the role of the major causal link in acts of free will, the latter appears to elude the iron grip of determinism. 
The self as a complex system

Though we have the concept of self and are generally aware of our own selves, the myriads of neurochemical processes linked with our self-networks are not reflected in our consciousness, and occur autonomously. We are aware of many of our beliefs - perhaps most of those when we care to examine ourselves - but we do not consciously control the way the self-linked beliefs are invoked and, in turn, operate to let loose our emotions in association with the operations of the neural valuing system. We are often aware of the ebb and flow of our emotions that generate our feelings, but the feelings are our very own precisely because the emotions constitute an amazing record of our innumerable life-long specifically personal experiences that keep on assembling our self-network ceaselessly. And, we are never aware of the workings of the psychological value-system though we routinely experience the positive and negative feelings generated from it, and our body responds with almost clock-like regularity to the affects that call into play the reward-punishment network.

Our brain is equipped with the capacity to make a map of the functioning of our body and to constantly assess that map so as to keep the body on a course of well-being by setting in motion innumerable corrective processes if need be. At the next level, it makes a map of the world around us and of the events in it - it constantly examines that map and prepares strategies to make good use of these events. And finally, it makes a map of our mind, i.e., a map of its own activities, constantly assesses the map, and never ceases to work out strategies to keep it on a course of well-being, fit to make further strategies, and to extract pleasure out of our existence. All this constitutes an amazingly complex process where large scale neural assemblies operate to carry on their respective functions and communicate with one another by means of synchronized oscillatory waves of neurochemical messaging. The entire machinery of the brain is a complex system made up of subsystems that are complex themselves. And the brain, in turn, operates within an enveloping hierarchy of complex systems - the body, groups of individuals (child and mother, family, peer groups), communities, cultures, societies, governments, and so on. At every level of this hierarchy, there operate amplifying and 
stabilizing factors (referred to as control and feedback systems by engineers) that lead to changing modes of behavior - a process of great adaptive value.

Within this vast and convoluted hierarchy, there resides the self-network. It is made up of a large number of neural assemblies - complex systems themselves - while, from the psychological point of view, being a system involving personal beliefs, memories, emotions and affects, where the latter is assembled around the reward-punishment system.

Among the large number of interacting components of the self-network, engaged in constant dynamic interaction with innumerable other networks in the brain, there operate the amplifying and stabilizing influences resulting from the affects and emotions. The amplifying factors produce local instabilities while the stabilizing ones are responsible for global integrity and coherence. Between them they generate innumerable modes of operation of the self - the infinitely nuanced moods, attitudes, and personality traits of an individual. A great number of such control mechanisms operate in parallel within the grand orchestra of the mind - an orchestra in which there is no single master conducting the show.

A phenomenal expression of the self is consciousness - that interface of the mind through which it examines its impressions and theories of the world, and tries to fit these with'reality'. The mind, of course, can never access reality as it is - it goes on making guesses, inferences, and interpretations, and testing these against the continuing impact of reality on itself. Consciousness is the cognitive face of self through which the latter focuses on objects, events, and ideas, and gets these assessed by invoking a shared world-view, made up of shared rules and shared logic. Consciousness is that arena where cognitive factors operate with their moorings in the unconscious self. And, finally, consciousness is that faculty of the mind that enables it to look back into itself, once again in terms of some shared world-view, as part of a cognitive endeavor.

Even when engaged in activities based on a shared world-view, the self leaves its stamp implicitly and invisibly, but also visibly when one cares to look at details. A group of 
young men visiting a restaurant for coffee and snacks all behave in accordance with certain house rules and norms of behavior accepted implicitly by almost all the customers. They stand in queue, pay at the cash counter, take their chosen items from the selfservice kiosk, and then choose their respective seats along with their companions for a relaxed half hour or so. Since all follow similar rules and norms there is a good degree of similarity in their behavior. But innumerable differences can be found in details - in the way they sit and talk, in the manner in which they share jokes, in the manner in which some smile silently with their eyes while some others laugh out loudly, in the way they conduct an argument, with some reasoning softly and others raising their voice in heated disagreement - all these small things speak of the immensely varied manner in which their self gets expressed. Some of these appear to be too insignificant matters of detail to be termed the exercise of free will - one young man looking at people around him while sipping coffee while one other looking down introspectively at his cup and seemingly not paying attention. But insignificant or not, a dividing line is discernible between activities possessing a common character and those that are individual in nature.

In summary, the self is a complex system (see [46]) with structuration at various levels, with built in control mechanisms involving amplification and stabilization in diverse processes operating in parallel, where it appears impossible to describe in terms of a compressed algorithm the entire spectrum of dynamic behavior of the self-network including its expression in the form of amazingly varied and subtle psychological modes.

Is the operation of the self-network self-determined? Can it be determined as to how the self will get expressed in the action and thought of an individual in a given situation?

The self-network is not self-determined. It responds to what is going on around it. The mind has memories, plans, expectations, preferences, in the context of which the self responds, frst, to streams of messages arriving from other neural aggregates of the brain in the form of waves of excitations and de-excitations and, secondly, to myriads of sensations received from the social and the natural environment from which the mind picks out the salient ones in accordance with its current state of receptivity while a host 
of other inputs are received, processed, and stored without our awareness.

The response of the self-network is, moreover, not a passive one. It is active in nature in that it amplifies the perception received from some of the internal and external messages it receives, smothers some others, and carries on an orchestration of its own. If the waves of the oceans are complex, the waves that rise and fall within the brain are even more so.

Is the ocean a self-determined system? Obviously not. The waves that rise and fall in it are all in response to myriads of interactions with the wind systems that brush its surface, to under-water disturbances, to geo-seismic events, to complex heating and cooling effects, to pulls and pushes exerted by the moon, to the pre-existing wave patterns and under-water currents, and to a host of other causal effects from marine life, floating objects, and objects of diverse descriptions that are constantly getting hurled into it. At some places the stresses and strains get amplified to produce frighteningly huge waves which either break or die down subsequently - at some others, waves of some other description are in the process of being generated. It is mindless to assert that, given the knowledge of the state of the ocean and of all that to which it responds, and given the laws followed by it, the future behavior of the ocean is fully determined. Mindless, because it is absolutely of no use. No self-respecting scientist ever looks for such all-embracing knowledge, though one may very well have a somewhat similar idea lodged in the back of his mind. The oceans do constitute a self-determined system but only in the sense of the statement being a truism.

A level-headed scientist may look at a localized system of oceanic waves and, taking into account the major factors that can possibly determine its dynamical behavior, tries to fathom out the future course of the currents, the swellings, the water level, the variation of roughness, all to within certain limits of accuracy and to within a certain time horizon. There are, once again, two things involved here. One is the matter of how things get determined in themselves, and the other is the matter of how we can determine their occurrence. Of the first, very little can be said in general. However, a sobering idea of what it involves can be had by creating a simplified model of water waves in a confined 
space where everything is known: the initial state of the system, the external influence in the form of specified boundary conditions, and the dynamical laws governing the mass of water - namely, the Navier-Stokes equations of hydrodynamics. Even so, the the model turns out to be too complex. The equations of hydrodynamics are non-linear, involving inherently amplifying and stabilizing factors that can operate simultaneously at various small regions within the mass, and even small uncertainties in the state of the system can lead to distinct modes of behavior. Turbulence may break out, shock waves may be generated. And the statement that things get completely determined in themselves turns out to be so vague as to be utterly hollow. And, it is at such an uncertain frontier that the issue of things being determined in themselves subtly merges with the one of how we can determine the course of things from the knowledge that we happen to have of the system we are looking at.

Determined and determinable. When we say that this or that system is a deterministic one, we actually mean that, given a knowledge of its present state and its mechanism of operation one can determine how its state will unfold in time. Even Assuming that the 'knowledge of the present state' and the 'mechanisms of operation' can be ascertained (two very big suppositions) there is no escape from the ubiquitous 'sensitivity to initial conditions' - the processes of amplification and the counterbalancing ones of stabilization, the ones of local instability counterbalanced by global stability, and the resulting complexities involved in prediction. There are fluctuations in everything we predict - small local variations in behavior that arise from causes too fine and detailed to have been included in the explanatory scheme we base our prediction on. And there are various different modes of behavior that appear as emergent phenomena - phenomena that appear as almost ghostly apparitions from within the folds of complexity.

A young man smoking a cigarette and taking a walk - absently flicking the ash off the cigarette without bothering to look at what he is doing - too small an incident to have a tangible cause, but one having some cause nevertheless - perhaps in the activity of a small group of neurons receiving and giving off signals... . We will, for our present purpose, take no notice of such small and spontaneously occurring events, generated by apparently insignificant fluctuations within the mental processes. 
But, on the other hand, look at the young man walking alongside that charming young lady, each talking incessantly and, at the same time, soaking in the animated talk of the other. Suddenly, a small remark from one has a strange effect on the other. The young man goes silent, head bent, eyes vacant. His mood has swung. A small and perhaps a somewhat frivolous remark from the unsuspecting young lady has had an amazingly exaggerated effect on her companion. His self-network has been greatly agitated. A stream of molecules have been released and have got attached to specific neural sites resulting in a neurochemical wave reaching out to other neural aggregates. All this is determined by the inner mechanisms of the self-network. The young man suddenly takes leave of the lady, leaving her perplexed. Another young man under similar circumstances would, perhaps, have taken his charming companion to a cafeteria for a pleasurable cup of coffee. Each to his own free will .... .

\section{Free will: the causal expression of self}

Now is the time to spell it out: free will is the causal expression of the self of an individual.

And, free will is free because it isn't constrained by shared principles, rules, and worldview.

Free will is not in conflict with determinism, whatever that term is supposed to mean. Free will is not free of causal linkages, but it is free of the constraints caused by factors outside the private periphery of the self. To be sure, every action of ours, every thought that flows in our mind in some given external constraint, have both types of causal linkage - factors shared in common by a group, a community, or a society, and those that are specific to our self-network. Among these actions and thoughts are the ones we refer to as products of exercise of free will because as we attempt to trace back the causal links to these we seem to 'lose the trail' at some point, failing to explain their occurrence in terms of our known stock of knowledge, accepted principles and shared beliefs. The latter prove inadequate as explanatory factors precisely because various different persons under similar circumstances come up with different actions and different thoughts. 
It has been observed [36] that free will is an uncaused decision by the self of an agent. In the present essay, I attempt to examine the self to uncover the causal roots of free will that is only apparently uncaused.

\section{Lingering questions: where to locate freedom}

What I have said so far seems all very fine. But it gives the feeling that there is really no choice involved in the exercise of free will or, for that matter, in the making of an inductive inference. All that is achieved in what I have said is to seemingly explain away the apparent incompatibility of free will with determinism by invoking the complex machinery of the self.

I seem to have restored the lost threads of determinism in the form of the workings of the self-network. The real question, however is, looking at the action or thought of a person under given circumstances, could that person have acted or thought otherwise? While all I have said above seems to engender an answer in the negative, we will find in the course of this essay, that there is some sense in which one can respond to this question in the affirmative too.

We thus ask the question, is there, then, no element of genuine choice involved in the exercise of free will? Let me first recall what the earlier pages of this essay tell us in this regard, pruned of all background stuff.

\section{Free will and inductive inference: recalling the basic ideas}

This section is devoted to the recollection of material presented in earlier sections along with a few clarifications.

I have referred to the knowledge base stored in our mind (three plus three is six; all bodies attract by the force of gravitation; Shakespeare wrote Othello; $E=m c^{2}$; the doctor is scheduled to examine my child in the evening; ...), our memories, our beliefs, our affects, 
emotions, and feelings, and our neural value-network. To this list I could add such things as our fantasies, desires, drives, and so on - these are important in themselves and, in fact, influence much of our psychological life, but will not feature in this present essay.

Among these, the knowledge base is, to all intents and purposes, detached from the selfnetwork and, in particular, from our emotions (see section titled Preamble, see also [26]). As I have mentioned above, the individual items of knowledge and, by the same token, the total store of knowledge, is tied to the personal biography of an individual. It may so happen, for instance, that a scientist has, through personal commitment, interest, and diligence, read up a huge mass of material relevant to her subject, far outstripping other colleagues of hers in this respect. But when she recalls and makes use, for her research purpose, of some particular item belonging to her knowledge base her doing so does not evoke affects or emotions. Of course, a great deal of emotions is roused if the said act helps her solve some long-standing mystery in her subject area, but that is a different matter altogether.

Along with the knowledge base, there are shared beliefs that can also be assumed to be detached from the self-network, at least partly. Some beliefs and principles are almost universal (everything is determined by the initial state of the universe; Einstein was a great scientist; one should try not to hurt others), some are less so but still shared by large groups of people regardless of their truth value (immorality is to be dealt with firmly; sexual excess will be followed by failing health; intelligence is linked to the genes). On the other hand, there are beliefs and principles that are almost entirely of a personal nature (there is insanity in my family and I will be overtaken by it some day; I have been wronged in life, and I will spare none; all my tormentors will be punished one day). I speak of beliefs and principles in the same breath since beliefs are generally of the nature of rules and principles we go by in our life, the more so when a belief is hooked onto our self-network. The more personal a belief is, the more it is laden with a valuejudgment, the more intense are the emotions attached to it, and the more insidiously it influences our judgments and actions. 
As we engage in an action or thought, some or all these resources lodged in our mind get invoked by means of the ongoing interactions among the neural assemblies in the brain, along with the release of a number of specific molecules and their attachment to specific sites that activates the neural value-system, this last-named playing the role of a guiding spirit in our actions and thoughts by way of approving or frowning upon the bits of activity through which the mind proceeds in its business.

In an act of making an inference, the resources principally made use of by the inferring mind are the knowledge base and the beliefs - the more widely accepted or shared ones among the latter. The pieces of knowledge and the beliefs invoked are generally in the form of principles or rules ('if this then that', or 'since this hence that') by means of which the inference proceeds. At times, the inferential process reaches some specific conclusion ('from all evidence, arguments, and counter-arguments, the accused is proven guilty beyond doubt'). On the other hand, it is more generally the case that the inference remains inconclusive, with several alternative conclusions making their appearance in the realm of possibility (my friend promised to come to-day - he must have fallen ill, or else must have had to leave station on urgent business). As explained in [26], one then has to guess, and to guess in the right direction. It is then that the inferring mind makes use of resources of dubious credentials - half-remembered snippets of knowledge, unfounded information, half-baked wisdom, beliefs of a personal nature, heuristics and hunches (see [15]), vague clues, memory laden with emotion - in short, resources linked in some measure to the self of the inferring individual - resources associated with affects and emotional valence.

This, for me, seems to be a plausible description of how inferential processes take place in the human mind. The actual neural processes, however, are completely out of the scope of this description since there is no clue as to how the various psychological resources and their dynamical interactions are represented at the neural level.

What is to be noted in the context of this description is that the possibility of 'alternatives' and a choice between those can be admitted with reference to the cognitive tasks of inference-making where there is considerable role of shared world-view, shared 
knowledge, and shared principles of inference.

On the other hand, it is equally likely that there occur mental process more heavily dependent on personal psychological resources where the possibility of alternatives appearing in virtue of inconclusive use of shared resources does not arise. While there may occur processes that are part cognitive and part self-psychological (I use the term 'selfpsychological' here to refer to psychological processes in which self-linked resources are made use of), the other kind of a predominantly self-psychological nature appears to be relevant to a wide spectrum of actions and thoughts in which we engage, many of which appear as exercise of free will. The question of alternatives does not arise in these processes in the same way as in the other cognitive processes mentioned above. These are driven to a large extent by personal beliefs, emotions, and affects, and are not directed towards a 'conclusion' in the same way as the other cognitive processes are. Rather, starting from a certain external and internal context, these self-psychological processes proceed along some entangled causal chain depending on the workings of the self-network and end up in a 'result' that appears as an exercise of free will.

Two neighbors (call them A and B) are engaged in a bitter dispute over the possession of a small plot of land having a common boundary with the estate of each of them. In a fit of blinding rage $\mathrm{A}$ strikes a blow to $\mathrm{B}$ with a metal rod lying close at hand, and $\mathrm{B}$ is immediately rushed to the hospital. In this not-so-rare incident, $\mathrm{A}$ is said to have 'chosen' the 'option' of physical violence over several other 'options' of less violent resolution of the dispute. But a group of impartial men of the locality, when asked to give their opinion on the matter, inform an onlooker that $\mathrm{A}$ is not of a disposition to even think of these other options - he is ever bent upon using physical violence as the principal means of persuading an opponent. The interested onlooker, on further inquiry, learns that A has had an unfortunate childhood, and is currently having problems with his wife - that he does not have much of an educational or cultural background, routinely beats his children, and is devoted to drinking. $\mathrm{B}$, on the other hand, is of a milder disposition, and 'in consequence', has suffered at the hands of A.

In what sense can the actions of $\mathrm{A}$ and $\mathrm{B}$ in the dispute be said to constitute instances 
of free will, when it appears that the outcome of the dispute was almost preordained by the very nature and disposition of the two disputants? Herein lies the central issue. The two have acted according to their own free will, not because of whether or not their actions are determined by the dispositions of the two and by the circumstances of the case. They have exercised their respective free wills precisely because two other persons (call them $\mathrm{C}$ and D) in the same situation would possibly have acted otherwise.

And it is here that a very big question keeps on bothering us. We feel in our guts that $A$ could really have done otherwise. But, in what sense? That is what we will now turn to. Before that, we briefly look at the same question, but now in the context of a cognitive act of inductive inference.

Two friends (call them A and B once again) working in different laboratories are engaged in a friendly rivalry in their chosen task of determining the structure of a complex biological molecule. The race is exciting to both and each of them works hard in his own way. But it is B who succeeds by making good use of a novel hypothesis that later proves useful, even before A has barely got to the depth of the problem. A teacher of theirs from their earlier college days when both used to attend her class recalls an incident when both did ordinarily in a class test but B came back doing exceedingly well in the next test while A's performance was again quite ordinary. What this small incident tells us is that B engages in self-examination and self-improvement, and is a good learner from failures, but $\mathrm{A}$ is not.

Self-examination, self-improvement, and learning, herein lies the ultimate source of 'alternatives' in acts of cognition as also in the exercise of free will. As I have promised above, this is what we will now turn to.

\section{Learning and self-improvement}

An act of free will of an individual in some given context is principally the result of operation of his self-linked psychological resources. Operating together, these resources produce an outcome that seem to be causally determined, with little room for alterna- 
tives. The fact that some other individual could have acted otherwise under the same circumstances will not directly concern us here. We ask the question, could this same individual not have acted otherwise?

The psychological resources of an individual are all produced in a life-long process. To be sure, these are all built upon factors inherited in the long history of biological evolution as also by genetic transmission. But, these may be referred to as the 'fixed assets' around which the infinite multitude of experiences and interactions undergone by the individual all contribute to his knowledge base, his shared world-view, his memory, his personal beliefs, and his emotions. His affects and his neural value-network are mostly of evolutionary origin but the way these operate within the matrix of these other psychological resources is specific to his developmental history.

The stock of the psychological resources of the individual in question and the mode of their operation at the present point of time depend on this developmental history. Given the developmental history, an act of free will is causally determined by the disposition of his present psychological resources that follow their own course, and is 'beyond his control' under the present circumstances. But, can it be that the same individual could have modified his own developmental history at some earlier time so as to have been endowed with a more enriched stock of psychological resources now?.

On the face of it, the answer would seem to be No. Since there can't be alternative possibilities to the actions and thoughts of the person now, similar considerations would tell us that there couldn't have been alternative possibilities to his developmental history at earlier points of time either.

It all seems to relate to the insurmountable problem of bootsrapping - how can a person, making use of his own psychological resources, enrich these very resources so as to be endowed with the capacity of engaging in a novel mode of action or thought at some later point of time? In physics, it is known that a mechanical system cannot generate momentum all by itself. In logic there is the problem of self-reference: a system cannot reproduce or describe its own activities completely. 
But an individual is not a closed system. He goes through an incessant learning process by interacting with other objects, events, and individuals around him. It is precisely the learning process by which his stock of psychological resources keeps on being assembled and enriched. He learns in innumerable ways. Indeed, it is inductive inference that constitutes the major means of his learning. However, once again, the same old problem of the self trying to modify its own development appears to raise its head.

Two students (call them A and B as before) of similar background are being taught in a class. One day the teacher tells the students that a certain book available in the library contains a lot of additional information on the subject being taught. Of the two students, B immediately visits the library, borrows a copy of the book, and spends the night assimilating the mass of interesting information it contains. The other student, A, in contrast, shows little interest in even having a cursory glance at the book. Many years later, B is found to succeed in establishing the structure of a complex biomolecule when A, engaged in similar pursuit, fails to find a way to solve the problem.

This example of the two students seems to tell us that a person continues to remain captive to his own nature throughout life: the psychological resources of A were not sufficient during his college days to make him a keen learner, and the continuing causal links in the development of his self-based resources resulted in his failure in the career of a front-line research worker several years later. As for B, his enriched self-based resources made him inquisitive and a keen learner, and it is that same inner richness that culminated in the success of his research endeavor, once again in a causally determined concatenation of psychological development. There seems to be no place here of an individual influencing his own developmental history in any real sense.

A person can be a good learner but that is no indication of her ability or propensity towards self-improvement. For, her childhood may have been spent in deprivation and that may have resulted in a strengthened will to learn and to out-perform her more fortunate friends at school whose affluence worked in their favor. The resolve to learn is a result of her current state of poverty and misfortune and the response of her current psychological resources to her conditions. An iron will to learn is a great thing, 
but it still falls short of being a factor that can alter her future course of development compared to the currently running course. The crucial question to ask is, how can the complex system constituting the mind of a person alter its own future behavior and response to various external contexts or, to put it differently, how can the mind alter the constitution of its own self-based psychological resources? The answer, of course, is: self-examination and self-improvement.

Learning enriches the knowledge base and the shared world-view that leads to an improved cognitive ability to make effective and useful inferences at later points of time. But the propensity to learn is determined by the current disposition of the self and that disposition can be altered only by self-examination and self-improvement, and it is this that creates the possibility of alternative modes of exercise of free will at later points of time.

But what, after all, is self-examination and self-improvement? Is it not the same thing as learning? Is it not logically fallacious to speak of a system altering its own course of development? Can it really get us around the problem of bootstrapping?

As I write these lines, appearing to explain how self-examination and self-improvement work, I feel hopelessly inadequate, and can only attempt to convey in broad outline why the two are of crucial relevance in the inquiry into what 'freedom' of will really consists of.

Self-examination and self-improvement are issues of great depth in the matter of human existence, and yet it is this deeper question that bears upon the issue of everyday exercise of free will as well. At the cost of repetition and some hyperbole, I represent the situation as follows: if I grab at the fleeting half-chance of self-examination and self-enrichment that has come my way now, I will have a more enriched repertoire of psychological resources tomorrow, so that my actions and thoughts tomorrow will be different than they would be if I ducked away from this one chance of self-examination given me now, perhaps fortuitously, perhaps once in a lifetime. 
Self-improvement is, in a sense, close to what Robert Kane calls 'self-forming action' (see [19]), to which he attaches great relevance in the context of free will. However, Kane's mode of analysis, rich and nuanced as it is, and his concerns, differ from mine. I have to state, though, that I have been influenced in a major way by his views.

First, the issue of self-reference and bootstrapping. Self reference poses a problem only when a system, making use of its own resources, tries to describe itself in its entirety. There is no logical problem with one part of the system acting on the other or describing it and even modifying it. Or, for instance, generating a code for describing its own structure and mode of functioning. For the purpose of this essay, the issue of selfreference can be be looked at as a paradox that we will leave alone as one not of great relevance.

Of greater relevance is the question as to whether self-examination is not the same thing as learning. There is no harm in looking at self-examination as a learning process, provided one distinguishes it from other forms of learning. There are two instances of learning involved here - learning how to self-examine and what significance it holds, and learning from the self-examination, drawing lessons from it, and acting on the basis of those lessons.

As I have indicated above, learning enables one to make a more effective choice from among alternatives in a future cognitive act of inference, but it need not alter the mode of working of the self-linked resources that get involved in an act of willing.

A student afflicted with the propensity to learn is constantly rushing to the library, borrowing books, and pouring over those in the dead of night. But he may still be lacking in the quality of self-introspection. He may still have deep problems in his family life later on and be incapable of sorting those out. Pouring over books adds to his knowledge base and expands his repertoire of shared beliefs and perceptions, but may still fall short of making him bold enough to confront himself, to accept his telling shortcomings in social life, and to lock horns with his own deeply personal beliefs. 
What is involved here is learning to look at one's own self, to go through the turmoil of conflicting emotions as one does that, and to bring under the scrutiny of his own deliberations at least some part of his own self-processes that he was so long not aware of. The diligent student may even be aware that he is having problems in his social life but may not have learnt to engage with those since that requires him to cross a threshold - one that generally causes pain and anguish.

This is something that even a highly learned person may have to learn, and learn the hard way, and this is where one with little educational background may overtake him. But how does one learn it? Self-introspection cannot be learnt all by oneself - like every other thing in life it has to be learnt from life itself, from others engaged in the broad arena of life.

But the old problem raises its head once again. Two young individuals happen to meet an elderly man who narrates to them the story of his life, in which he underlines how he confronted himself on several occasions at critical junctures and, in consequence, has gained in courage, conviction and inner tranquility. Of the two young persons, one is deeply moved on hearing this and starts looking at his own beliefs, personal preferences, and drives, thereafter delving ever deeper into his own developmental history and gradually coming to understand and engage with the conflicts and turmoils within him. But his friend remains unmoved and goes on living the same old life without self-doubt bothering him in the least.

Does this not mean that our current psychological resources determine whether or not, given a chance to learn the value of self-examination, we actually make good use of that chance? And, does this not then mean that the future course of life of an individual is determined completely by her current state of the mind, that two distinct individuals passing through similar successions of external circumstances will each act and think at every point of time in accordance with her own current state of the mind?

There is substance in this point of view, according to which the iron grip of determinism necessarily smothers all possibility of free will (free, that is, in the commonly accepted 
sense of the term), even the possibility of influencing one's will at a future time by engaging in self-examination now.

But we forget the complexity of the self-network, and the variety and diversity that life offers. Amidst this complexity, variety and diversity, determinism and predictability take a backseat. Put differently, determinism and predictability are to be interpreted appropriately in the context of complexity, variety, and diversity.

All our actions and thoughts are events that occur under the confluence of external and internal contexts, both of which involve complexity. As for the internal context where the self-network operates within the larger ambit of the mind at large, there is the incessant ebb and flow of emotions, alterations in attitude, mood swings, and small fluctuations occurring here and there, all going on in a curious blend of predictability and un-predictability, more so when combined with the infinite variety, diversity and changing scenario that the world at large presents to us.

Within this chaos, causal links are constantly set up and broken. These are the links that help us predict that my wife is going to have a good day to-day, that two friends of mine are likely to have a big altercation in the pub this evening over a proposed business deal, and that I will have to spend a harassing half-hour with my boss in the office to-morrow. In a complex set-up, small fluctuations occur ceaselessly: I suddenly remember where to find my favorite pen that I lost yesterday; my kid, in his haste to run to the playing field, forgets to plant the regulation good-by kiss on his mom's cheek; I pick up a hamburger from the lunch counter without looking at the tempting bowl of noodles lying beside. But causal links are still discernible helping us to move ahead in the business of life, helping us to make inferences by guessing and guessing correctly, helping us carry on our scientific investigations and provide an effective interpretation of the world in the form of theories.

All our predictions, guesses, and inferences are limited by a time horizon during which we can effectively foresee the causal links that operate in the world within us and also those without. Beyond the time horizon, the complexity takes over, new causal links 
become relevant, new modes of behavior emerge and the earlier inferences, guesses, and theories come under scrutiny. Kaleidoscopic changes take place inside our mind as also outside.

An occasion arises when I have an opportunity to learn about something that concerns me in a big way, say, about the psychology of adolescents, which does concern me since my son has been found in recent days to behave strangely. However, I let the opportunity go. A few weeks later, one evening I find my son forlornly sitting on our doorstep, and the very sight of him galvanizes me into action when I procure a book from a friend and pour over it, trying to guess all the while what can have gone wrong with my child. The world outside has changed: my son is plainly in a state of despair; the mind is in a perceptive mood - the confluence of the two produces an attitude of keen perception and feverish inquiry in me.

Some ten years back, my dad had called me to his bedside and had tried to impress upon me that I was then under the sway of a set of wrong perceptions about the world, which could inflict damage on me. I did not pay heed and had left his bedside with a sour face. Now, ten years hence when he is no more, I suddenly recall his sadness at my refusal to confront myself and also recall how he had always been so very keen to help me in small ways and to ease the turmoil within me. A wave sweeps through my mind, and the same me who had been headstrong ten years back now find myself trying desperately to scratch the hard and roughened surface of my own mind so that I can communicate with my troubled soul.

The world never ceases to change. Ebbs and tides never cease to rock the mind around. The two come together in a dizzying variety of combinations, in which the mind reacts to perceptions in so many different ways - old beliefs get revised, the knowledge base is modified and extended, some existing memories are erased or apparently fade into oblivion, only to spring back with renewed emotions without discernible cause, new memories with emotional tags are formed, deeply personal views suddenly get rattled.

There are individuals to whom other people and the world around them present little 
variety. For them the world remains the same day in day out, with only backbreaking toil to do, and the urgent needs of the hour to meet. There are people who, in spite of their similarly oppressive circumstances, find a way to fulfillment by strange quirks of developmental history. And there are people who are blessed with opportunities in life: opportunities to learn and opportunities to examine their soul. Learning plays the same role in inductive inference that self-examination does in the exercise of free will.

About to enter into a business deal with a friend, I devote days to inquire into and be informed of his recent records... his debacle in the stock market, his unhappy family life, his earlier history of floating companies and then folding those up, none of which he had disclosed to me. In spite of his own declared business and his present proposal looking solid on paper, I develop a gut feeling he is out to play games with me I am not too adept in. On a strong hunch, I turn away from the deal.

Self-examination is akin to learning - but is learning of a very special kind. It is not borrowing a book and studying, nor tracking the records of a would-be business associate. Here one looks at and studies oneself, questions one's own closely held beliefs, tries to divert the tide of one's own emotions, and risks getting into a turmoil. Is it logically possible for the mind to engage in self-reference so as to be able to do all this?

Once again, we have to recognize that the mind is a complex system. Neural assemblies of all descriptions communicate with one another by the complex ebb and flow of electrochemical waves of synchronized oscillations. One part of the mind 'studies' and makes a map of the doings of another, and then that other part engages in the reverse process of 'studying' and creating a map of the former .... maybe, the entire map is transferred to yet a third part that acts back in accordance with what the emotions and the value-network tell it about the map so created.

People are confronting themselves everyday everywhere - from the most oppressed, deprived, and most despondent of men, to the one blessed with huge resources, huge power and equally huge moral agony. Some are turning away from the pain and turmoil 
involved, while others are plodding ahead with courage, recreating their life and their problem-ridden existence in the company of their fellow-beings in this world.

Learning is the process that one engages in now so as to make possible a successful cognitive act of inference, perhaps involving a choice among possible alternatives, at a later point of time. Learning enriches the shared world-view of a person and also enriches her psychological resources tied to a greater extent with her own self. But the most effective enrichment of the self-linked psychological resources comes with selfintrospection which, once again, is a process that an individual engages in now so as to acquire the ability to act otherwise at a later point of time as compared with what she would be doing were she not to engage in that significant act of self-examination.

Self-introspection is one act that requires deliberation. It requires awareness of the self. It requires one's conscious mind to be perceptive enough to register signals from her self-network to which she was unresponsive so long. It requires will to do that, and that will is harnessed as the mind, in a constant state of ebb and flow, finds itself in an external context, equally possessed of ceaseless processes of change in variety and diversity, in some appropriate conjunction.

And herein one finds probability making its appearance. We are now looking at one complex system coming in interaction with another and making a response, depending on what faces they present to each other. For, complex systems that they are, they have innumerable faces each and innumerable different modes of behavior.

The waters of the ocean are in constant interaction with the atmosphere overhead. Still, large swells in the ocean are not produced hourly - they are produced only when the two complex systems come in some appropriate conjunction, say, one involving a low pressure, a strong swirling wind, and a sudden under-water seismic disturbance. What is, however, of great relevance is that the oceans and the atmosphere being complex systems, such conjunctions do arise once in a while. The causal links are there to work their way as and when a conjunction occurs, and such conjunctions are likely to arise every now and then. Here is determinism and predictability thrown in a new light. 
Determinism continues to reign on a grand scale - seemingly like a hollow truism - involving the oceans, the geothermal system, the seismic occurrences, the atmosphere, the clouds, the heavenly bodies, the cosmic dynamics, the elementary particles, everything there is. Within this infinite horizon, there are islands of predictability based on causal links discovered here and there, some connected up with others into theories. And these theories are made use of in interpreting this part of the world and that, within limited horizons of space and time. In trying to stretch these horizons, we meet with obstacles where new causal links are to be discovered, and predictions are to be made in a new context.

And, this is exactly how we 'explain' free will. We explain it as a causal event in which our self-linked resources play a major role, as an event where large scale neural assemblies in the brain interact with one another, and as an event where the mind responds to appropriate conjunctions of external and internal contexts. Given the external context, it is only the repertoire of internal psychological resources that determines the act of free will and it is in this sense that the act involves no 'free choice'. It is, however, 'free' in the sense of not being subject to the constraints imposed by a shared world-view, by principles, 'rules', and 'logic' coming from a shared common pool. And finally, we explain how an act of free will involves real alternatives by locating those significant events of self-examination that occur at earlier times. At the same time, we locate the possibility of self-examination in the favorable conjunctions of internal and external factors that are not guaranteed to occur but are likely to occur sometime or other in the lifetime of an individual, perhaps several times over. It is in this sense that an act of free will is 'free' from the iron grip of determinism while still being the resultant of discernible causal links operating within limited horizons of space and time.

The causal links include communications between the conscious and deliberative part of the mind and the subterranean psychological resources of the self. The conscious mind is nothing more than the complex operation of yet another set of large scale neural assemblies hooked up with the self-network.

Even as I write glibly and knowingly about 'neural networks interacting by means of 
electrochemical waves of oscillations', neuroscientists are engaged in the hard grinding work in untying the knots of the deep tangle that constitutes our mind. One not belonging to their discipline can only have a glimpse of what they are doing, acquire a vague understanding as to the import of the latter, and make tentative suppositions. It is one thing to make statements of a general import and quite another to painstakingly unearth the causal links in a complex system, limited as these are in their scope in space and time.

However, deliberation works hand in hand with complex processes going on in the unconscious mind. And, as indicated above, unconscious emotional factors often trigger a bout of self-enrichment.

As I finish reading a novel by an author whom the world seems to have forgotten, I feel moved under a strange and inexplicable liberating influence. That same day I enroll in a rehab camp so as to come out of a lingering dependence on alcohol. Did that act of mine have anything to do with my experience of having read the book? I would never know for sure. What I am aware of is a deliberate act of self-introspection that preceded my decision. In the absence of that introspection I would not have acted as I actually did.

\section{Reasoned exercise of free will: the necessary and the contingent}

One frequently associates reason and rationality with free will. This appears to be in conflict with what I have been saying in this essay of mine where I seem to have equated the exercise of free will with action and thought guided by emotion-laden psychological factors associated with the self of an individual. I accept that there is ground for such an impression from what I have written. This section will, perhaps, set things in the right perspective while, at the same time, underlining the essential role of self-linked resources in the exercise of free will.

I have distinguished between shared mental resources such as the knowledge base, 
inter-subjective beliefs, and commonly accepted rules and principles on the one hand, and the self-linked ones involving emotional components on the other, but such distinction is only notional. Everything in the mind is associated with everything else, which is why the mind is such a complex system, almost as complex and infinite as the universe out there. Mental processes cannot be classified in a dichotomous either-or manner, and any classification can only be in the sense of a spectrum, where one part of the spectrum is perceived to be distinct from another while there exists a complex interlocking between the two through a continuous transition from one to the other.

Imagine the judge preparing the verdict in a complicated case that was stuck in the court for long years. The judge is constrained by voluminous documents covering all legal aspects of the case including meticulously laid down clauses of the juridical code that may prove to be relevant to it. The judge exercises her reason and rationality to the utmost in interpreting all the documents now lying before her but still at the end of the day it will have to be her interpretation that will go into the judgment. There are two things here finely blended into one.

In arriving at an interpretation consistent with all the documents that have piled up, the judge makes use of her reason and rationality, calling into play a stupendous amount of legal knowledge, experience, and wisdom. However, when we look closely at the terms that I have just listed, one finds that there are certain fringe areas that raise the possibility of the interpretation of one judge differing subtly from that of another if she (the second judge, that is) were to go through the same exercise. Evidently, there is some scope of the self-linked factors of the judge being called into play. Which is why the judgment can go for review, though that will still not remove all possibility of an alternative interpretation - there frequently, if not always, remains the lingering doubt that a person accused of murder and sentenced to capital punishment did not actually commit the murder. But all these constitute one of the two aspects I set out to elaborate. We will now leave all these possible self-related issues of interpretation aside, and look at the one thing that cannot possibly depend on self-related factors of the judge - namely, the legal knowledge that she bases her verdict upon. Who can deny that knowledge, even legal knowledge, is, to all intents and purposes, universal? But here 
again, there remains a question mark. While individual items of knowledge are indeed of universal validity, the total mass of knowledge relevant to the case under consideration is specific to the judge. One individual differs in thousand and one ways from others in her diligence, perseverance, commitment and qualities of perception that develop throughout her life and determine the mass of knowledge that will be in her command and the specific use she will be able to make of it. This indeed sets a judge apart from her colleagues and provides the basis of that extra respect that she commands in legal circles, apart from specifically self-related issues like her acumen, perspicacity, integrity, and independence.

I will not labor the point any more. The basic issue relating to free will, as I see it, reduces to whether and how we distinguish between the necessary (i.e., factors answering to reason and rationality) and the contingent (i.e., self-linked factors). Two leaves in a tree have the same general physical and biological structure characterizing them, but still they differ in a thousand and one small ways that may be described as contingent - ones that may be said to define their 'self. Two individuals from the same family have many things in common, not only in virtue of both being human beings but additionally in virtue of being members of the same family - still they differ in their fingerprints that depend on contingent factors in early developmental history in spite of being guided by genetic characteristics.

While the fingerprints of an individual are contingent features determined in her early developmental history, innumerable other contingent factors accumulate during the entire course of her development, many of which disappear without leaving any trace while the remaining ones leave their imprint upon her, especially upon her mind. Broadly speaking, all these factors taken together constitute her self, though in the context of the present essay, I have earlier mentioned only a number of those that I have found to be of relatively greater relevance in characterizing free will as I see it.

Every act of exercise of free will is possessed of general or necessary features that can be explained in correspondingly general terms by invoking concepts such as reason, rationality, and knowledge base of the person concerned. But the same general terms 
of reference fail to explain specific aspects of the act since these specific aspects may be found to differ for different individuals under similar circumstances, because these depend on contingent factors relating to those specific individuals. It is this that is often interpreted as free will being 'free' of the constraints of determinism.

Leaving aside the ontological aspect of the tenet of determinism, I repeat that the epistemological aspect of the tenet is often taken to be what determinism means: what we commonly mean by the term determinism is that, given sufficient knowledge base, one can explain and predict everything there is to explain and predict. But, 'knowledge base' includes not only the mechanisms underlying all the relevant processes, but all the contingent factors that determine the initial conditions as well. Let us grant that it is possible to know all the relevant mechanisms (the 'laws', that is; as I have already stated, this is a very big supposition indeed), but then what remains is the hugely relevant, but contingent set of initial conditions on which the mechanisms operate. Unless ones takes into account all the contingent factors involved, predictability vanishes into thin air. This, precisely, is the case with free will where the contingent factors reside in the self of an individual.

It is said that the laws of physics operate inexorably towards a future (thankfully, a distant one) of 'heat death', that is, an equilibrium configuration on a grand scale. But that is not what is relevant now and here. All our thoughts and activities are based on non-equilibrium configurations and processes where the detailed structures in space and time matter, and matter enormously because these include our very own life processes, our thoughts, aspirations, and hopes. And, all these configurations and processes depend on contingent factors along with necessary ones. The same apply, in particular, to the exercise of free will. An act of free will can be 'explained' only partially on the basis of what may be looked upon as 'necessary' aspects - the ones relating to reason and rationality. Recall that, in this sense, reason and rationality act as constraints rather than factors relating to freedom. What is really relevant to freedom are the contingent factors - all of those that relate to the self: the entire set of innumerable details relating to the developmental history of the individual, all those, that is, that leave an imprint upon her mind. What is relevant and interesting is that, our efforts at 
'explaining' an act of free will flounder when confronted with these contingent factors in virtue of these being hidden even from ourselves. The paradox of free will resides in this fact of all our actions and thoughts being stamped at once with necessity and contingency.

And, as I have stated repeatedly, this is precisely why free will appears to be free - appears to defy the iron grip of determinism. On the other hand, the 'freedom' is, in a manner of speaking, only an apparent one since free will is not free from the operation of correlations of a causal nature: the foundational position that we adopt is that all processes occur on the basis of causal correlations that can be determined by painstaking inquiry and investigation, at least partly and contextually, making possible successful predictions within limited horizons.

So, at the end of the day, is the question finally settled? Is free will really free? Is man genuinely free to exercise his will?

The answer to this question has to depend on what we mean to be free. As for me, the only real freedom lies in grabbing at chances to learn, to look at ourselves, to confront ourselves, and to enrich ourselves. Such chances do turn up. Whether or not we make use of those depend on how we have learnt to focus our awareness onto ourselves, to communicate with our very own selves, and to let reason work hand in hand with our emotions and value judgments. Setting up this communication is the ultimate thing in living an open life, in letting light shine on the twilight where our soul resides.

\section{Summary and concluding words}

First, a quick summing up (it has been a long monologue), and then a few generalizations. 


\section{The problem of induction and the problem of free will}

1. In this essay, aimed primarily at assembling a point of view with regard to free will, I have drawn a parallel with inductive inference since both inductive inference and free will are based on the use of self-linked psychological resources (see below) of an individual, namely, personal beliefs (as distinct from shared ones in common with other people), affects, emotions, and feelings along with the all-important psychological valuesystem. These are associated with a number of other ingredients such as fantasies, desires and drives that I have not referred to explicitly.

2. I adopt the position that all these psychological resources and the processes they participate in are based on electrochemical processes in the brain, involving neurons and their interactions, associated with numerous other physiological processes. I adopt the position that psychological processes are phenomenal appearances of underlying neural ones where the principal functional units are large neural assemblies rather than individual neurons, and where these large assemblies interact with one another by means of wavelike synchronous oscillations spread over various frequency bands. It is these complex waves that carry the 'information' produced by one functional unit to another, thereby making possible a global orchestration that preserves the integrity of our mental world in spite of the enormous diversity of mental processes.

3. Within the complex organization of the large scale neural networks, there is the self-network that is a complex system itself, made up of a number of large neural assemblies communicating with one another and with the rest of the brain systems. The functioning of the self-network involves the self-linked psychological resources mentioned above. According to the position adopted in this essay, it is the feature of complexity of the

self-network and the interacting neural networks of the brain that is of 
central relevance relating to events and processes in our mental life.

4. While inductive inference (discussed more fully in [26]) involves the cognitive face of the self, working in tandem with a commonly shared worldview made up of commonly accepted principles, rules, and logical presumptions, free will is linked to a greater extent with emotion-based processes that I refer to as 'self-psychological' ones. The dividing line between inductive inference and free will is not sharp, and there occur processes possessed of features of both.

5. It is said that both inductive inference and free will implies a 'choice' from among 'alternatives'. This essay tries to explain whether and in exactly what sense such choice can be said to be involved. In the case of free will, the very existence of the 'choice' is supposed to pose a problem with the tenet of determinism. In this essay, I have not engaged with the issue of determinism which I feel is too big to be of concrete relevance in our present context. On the other hand, I adopt the position that psychological processes have, associated with them, underlying neural ones that have causal links running between them that can, to a certain extent, be identified and made the basis of predictions (in terms of the psychological processes themselves) within a limited horizon. As mentioned above, the human mind is a complex system, with the self-network functioning as a complex system itself. Complexity, indeed, exists in all scales, and all psychological processes, including the making of inductive inference and the exercise of free will, is based on the interaction among complex systems. In particular, the external world is a huge complex system itself, and psychological processes are, in one sense, the continuing response of the mind (in association with the body) to the particular facet of the world that happens to be presented to it at this point of time or that.

6. As the mind engages in the task of responding to a conjunction of internal and external contexts, it makes use of its shared world-view made 
up of its knowledge base, and of commonly accepted beliefs, rules, principles, and logical presumptions. It may so happen that an adequate response is formed solely on the basis of this shared world-view. More commonly, however, the shared world-view leads to no unique position, and the question of a choice from among alternatives arises. This, for instance, is the case with inductive inference which is a cognitive process involving the shared world-view of an individual as also her self-linked psychological resources. The latter are made use of in arriving at an inference which is not guaranteed to be correct. On the other hand, there occur processes where the use of the shared world-view is secondary to a relatively more predominant role of self-linked psychological resources. In such cases the question of choice from among alternatives does not arise in the way it is commonly understood to.

7. When we speak of the choice involved in an act of exercise of free will what we actually refer to is the commonly observed fact that various different individuals of a similar disposition respond differently when placed under similar circumstances. In other words, free will is 'free' precisely because it is not subject to constraints of a commonly accepted and shared set of principles, beliefs, and values. While it is possible that, in an exercise of free will, the self-linked psychological resources are brought into action when a number of alternatives are presented to the self by the operation of the ingredients of a commonly shared world-view, it seems likely that that set of alternatives is not of primary relevance in the final response that the mind produces, since the latter is primarily a product of the operation of self-linked psychological resources regardless of the commonly shared world-view. What is of greater relevance here is the operation of emotion-driven processes, guided by the psychological value-system based on the activity of the so-called reward-punishment network in the brain. These processes lead the individual to a response that appears to be free from the shackles of determinism precisely because their mecha- 
nisms, which are hidden from us, do not conform to commonly accepted and shared rules and principles.

8. Thus, there is really no choice involved in any significant way in the exercise of free will when one looks at it in the context of the mental processes of a single individual, without comparing with how other individuals would respond under similar circumstances. On the other hand, it still makes sense to ask whether or not that same individual could do otherwise than what she actually does, i.e., the way she actually makes a response to some specified situation. While this seems paradoxical, things clear up once one gets to comprehend the sense it is intended to carry.

9. This brings us to the issue of self-examination and the associated process of self-improvement, where the latter involves an enrichment of selflinked psychological resources in the form of revision of one or more of the beliefs of a deeply personal nature, and of an alteration, at least to some extent, of the ebb and flow of emotions in one's mental processes - of an alteration in the way the psychological value-system operates, by way of an examination of the roots of one's own preferences and negative judgments about the world. As one engages in self-examination at any given point of time, it results in the possibility of an alternative course of response to internal and external contexts arising at later times. In other words, as one engages in self-examination now, one opens up the possibility of acting otherwise later, where the comparison is now with reference to the response that would result in case the self-examination were not to take place.

10. What determines whether an individual will engage in self-examination under given circumstances? Does it depend only on the disposition of the psychological resources of the individual at a given point of time? If so, the same old problem of determinism is ready to raise its head. 
However, self-examination constitutes a very special instance of learning. The role of learning is of great significance in the making of inferences, including ones of inductive inference. Learning expands and enriches the commonly shared pool of knowledge, beliefs, and inter-subjectively accepted logical principles. In case these ingredients fail to lead one to some specific response to a cognitive challenge, one is faced with the job of choosing between alternatives by bringing in one's self-linked psychological resources. But how and when does one learn? One does so under the impact of the world without, including instructions, suggestions, and various other types of messages from other members of the society. We learn from books, we learn from circumstances, we learn from exemplary behavior of people we admire, and we learn in thousand and one other ways.

Self-examination, as the name implies, involves an appraisal of one's own self, and is a very special instance of learning under the impact of circumstances. Here the self, in some particular mode and disposition of the self-ingredients that happens to have materialized at some point of time in the course of a ceaseless dynamic process of evolution, comes in conjunction with some particular facet of the world that happens to be presented to it. It is this conjunction that leads to self-examination and self-enrichment which, therefore, is probabilistic in nature, though based on definite causal links that can be discerned to within limits, where the limits arise because of the fact that one is now looking for causal links within complex systems. For instance, as an individual gets in touch with another person several times in succession, there may be just one occasion when the suggestions of that second person leads to an attempt of self-examination by the individual in question, because of some particular set of contingent circumstantial factors having come into play. 
11. It is self-introspection and self-enrichment that makes us ready to make adequate use of our reason and rationality. The exercise of free will covers a wide spectrum: from acts guided primarily by reason and rationality at one end, to those guided primarily by our self-linked psychological resources at the other. There is no act or thought that is completely free of the self-resources. What we mean by determinism and what we mean by freedom are, in fact, the two faces of reality - the necessary and the contingent. Reason and rationality represent and express the 'laws' of this world - at least our interpretation of those - while what we mean by freedom resides in all the contingent factors of that same world. And, the self is contingent - contingent upon all the innumerable coincidences and conjunctions that occur during the lifetime of an individual and leave their imprint on her, especially on her mind. It behooves us to see and to comprehend that necessity and contingency are not two conflicting faces of nature. Nature is one single hugely complex entity, with myriads of parts correlated with one another by means of interactions that we can only guess at. It is our way of viewing nature that makes us interpret it in terms of necessity and contingency. Necessity appears to us as determinism while contingency appears as freedom. This is how it is with our own acts and thoughts too, where necessity and contingency appear to be in conflict for ever.

12. This essay has dwelt at some length on how the self-linked psychological resources come to play a major role in our mental life. It has also devoted itself to examining a number of features of complex systems including the ones of amplification leading to local instability and the counterposing influence of factors ensuring global stability. It has, in particular, underlined the role of emotions, aided by the psychological value-network, in leading to such instability and counter-stability, responsible for innumerable different modes of operation of the self-network, where such different modes of operation may be looked upon as emergent behavior in 
complex systems.

In looking at complex systems, I have outlined how determinism and predictability are to be interpreted in a manner somewhat different from the commonly adopted view of these. In particular, I have indicated that causal factors never cease to operate in the workings of a complex system interacting with complex systems of other descriptions. However, these causal mechanisms imply a kind of predictability that is strictly limited in scope, the validity of which is lost beyond a time horizon depending on the nature of the interacting systems under consideration. In a sense, such limitations on our predictability of events and phenomena is ubiquitous. The inherent limits of predictability in respect of complex systems are reached in scientific investigations that have a tendency to push against these limits, break these open, and discover new causal links, only to be confronted with re-established limits of predictability making their appearance further away.

\section{From individuals to societies... and on to mankind}

I feel that I have now earned the right to generalize and to look at societies made up of individuals and —why stop half way? — then at mankind!

Each of the large scale neural assemblies in the brain has its own built-in functionality involving the processing of incoming electrochemical information by the mass of the interconnected neurons it is made up of. The results of this processing are then exchanged between the various assemblies by means of waves of a complex nature sloshing around in the brain, and through direct neural pathways too.

This idea of describing mental processes is not a solidly established one and is nothing more than just a point of view. However, it appears to be tacitly shared by neuroscientists, and is consistent with a large body of findings in neuropsychology. In a vague 
way, it draws inspiration from the connectionist theory (or the parallel distributed processing model) of cognition and memory (the connectionist approach has a rich history, see [30]) and considers neural assemblies rather than individual neurons as parallel processing units. It is adopted in this essay as a kind of loosely defined background to what I have had to say on the characteristic features of free will. In the following paragraphs, I have made use of this point of view to draw an analogy between the workings of the mind of a single individual and the collective psyche of a society. I hope that this will be of some value to my readers.

This has a remarkable resemblance with how larger groups of men and women and entire human societies operate. A society of men and women is usually organized into units or groups that communicate and interact among themselves by various means, constituting functional units of diverse descriptions. Thus, there are children belonging to a class, teachers in a school, workers in a factory, the managerial and administrative unit in a business organization, the local council in a city, the federal government in a country, a political party, and so on, each operating in its own unique way. The individual persons belonging to all these groups and collections have similar constitutions in respect of their bodily structure, anatomy, physiology, and mental capacities while, at the same time, they participate in the common functionality of the respective groups.

I focus here on the common features of the individuals of a group while, in reality, each individual has his or her distinct personal identity too.

Transcending the level of individual existence and functioning, and also the level of functional groupings, the society as a whole is marked by its own existential features and characteristics. In other words, looking at the individuals as the 'neurons', and the various groups and organizations as the 'neural assemblies', one can, in a manner of speaking, look at the society as the collection of these assemblies where, at each level, one has a complex system belonging to another complex system at a 'higher level'. However, a simple-minded description in terms of 'lower' and 'higher' levels misses a number of features of major relevance relating to complexity. Finally, the society as a 
whole interacts with other societies of human beings.

Relegating individuals to the status of 'neurons' in a society looked upon as a 'brain' raises the specter of science fiction horrors. But that, obviously, is farthest from the spirit of all that I venture to write in this essay.

When one places the idea of complexity to the fore, the classical mode of description in terms of computational models of individuals and societies is avoided, though the classical computational models are important in their own right.

In this analogical view, the self-linked psychological resources of an individual find their analogous counterpart in the cultural features of a society. Within a society, there are cultures and sub-cultures. Indeed, various groups of individuals carry their own culture, their own specific way of behaving and responding. A political party has its own culture, a religious sect has a strong cultural trait of its own, and so on. Even a single family has its own micro-culture within all these cultural formations. The personal beliefs of an individual find their analogy in the cultural features of these various groups and human organizations. Indeed, major components of the self-linked beliefs of an individual are formed in virtue of the existence of that individual within these diverse cultural formations while, at the same time, the cultural features of a group are formed in virtue of complex interactions between individuals and all the various groups.

I will not pursue further this line of discourse since I am already deep into the danger area of loose speculation. Instead, I will now come to what I intend to say in this concluding section of my essay.

Just as in the case of an individual, a group of individuals can also be said to engage in acts of 'free will' where such an act distinguishes it from other similar groups under similar circumstances. We do not usually describe such activity as instances of free will, but every group does have its own culture, its own specific response to situations, and its very own ethos. 
Several groups of young college students are sitting with snacks and coffee in a cafeteria, members of each group exchanging pleasantries among themselves. An old man in tattered rags is found to collapse in front of the shop, gasping for breath. Most of the groups carry on their loud laughter and conversation, paying little attention to the incident. But one group of young persons immediately rush to the help of the hapless old man and get him first aid, and then further medical attention. Clearly, this particular group among all those sitting in the coffee shop has a culture and identity of its own. Given a situation, various different groups of men respond differently, all those different responses being alternative ways from which each particular group may, on the face of it, be said to 'choose' some particular alternative or other. But such 'choice' is no more than a convenient way of describing the specific response of one group as distinct from those of other similarly constituted groups. For instance, the group of students rushing forward to the help of the sick old man did not spend time in weighing between the relative merits of continuing with their pleasant gossiping and rising to provide urgently needed support - they 'spontaneously' rushed out in response to some tacitly felt common impulse without pausing to 'choose'.

As with a group of men, so with a larger society of men or a nation. Looking at the ways of governments and nation states, one finds infinitely many differences in the way they set up their relations with one another. Is it possible to speak of the cultural ethos of a nation while recognizing that the innumerable individuals and groups of men and women that it is composed of think and act differently? As I understand, one can indeed speak of the specific characteristics of a nation, though in a qualified sense, just as one can speak of the character trait of a single individual in spite of the innumerable pulls and pushes operating within his mind that cause him to have various distinct and conflicting tendencies, even though his outward behavior pattern at a given point of time is some resultant of all this multitude of disparate propensities. The idea of a nation or a large society of men engaging in self-introspection is not inconceivable though, understandably, such self-introspection is rare indeed, being possible only under exceptional circumstances and by exceptional means. It can happen, for instance, if one person or an influential group of persons of great stature, or even a government in power or, say, 
an opposition group, rises above others in a time of crisis and places before the people a set of novel ideas with some stirring message, around which the nation rallies.

And finally,..... on to mankind. Is it possible for mankind to self-examine and to turn over a new leaf? Is it conceivable that we, men and women of this world, are capable of looking collectively and meaningfully at the destruction and corrosion that is eating away at our soul? Is there yet a 'free will' left in mankind? 


\section{References}

[1] David M. Armstrong, Belief, Truth and Knowledge, Cambridge University Press, Cambridge (1973).

[2] M.T. Banich and S. Floresco, 'Reward systems, cognition, and emotion: Introduction to the special issue', Cognitive, Affective, \& Behavioral Neuroscience, 19, 409-414 (2019).

[3] Kent C. Berridge and Piotr Winkielman, 'What is an unconscious emotion? (The case for unconscious "liking”)', Cognition and Emotion, 17(2), 181-211 (2003).

[4] Margaret A. Boden, The Creative Mind: Myths and Mechanisms, Routledge, London (2004).

[5] Carl I. Cohen, 'Working towards a liberatory psychiatry? Radicalizing the science of human psychology and behavior', in [6] (2008).

[6] Carl Cohen and Sam Timimi (ed.), Liberatory Psychiatry: Philosophy, Politics, and Mental Health, Cambridge University Press, Cambridge (2008).

[7] Michael H. Connors and Peter W. Halligan, 'A cognitive account of belief: a tentative road map', Front. Psychol., 5, 1588-1607 (2014).

[8] Antonio Damasio, Self Comes to Mind: Constructing the Conscious Brain, Pantheon Books, New York (2010).

[9] Ap Dijksterhuis, 'Think Different: The Merits of Unconscious Thought in Preference Development and Decision Making, Journal of Personality and Social Psychology, $87: 5,586-598$ (2004).

[10] A Dijksterhuis, M.W. Bos, L.F. Nordgren, and R.B. van Baaren, 'On making the right choice: The deliberation-without-attention effect', Science, 311, 1005-1007 (2006).

[11] Ap Dijksterhuis and Loran F. Nordgren, 'A Theory of Unconscious Thought', Perspectives on Psychological Science, 1:2, 95-109 (2006). 
[12] John Martin Fischer, Robert Kane, Derk Pereboom, and Manuel Vargas, Four Views on Free Will, Blackwell Publishing, Oxford (2007).

[13] Peter Gärdenfors, Conceptual spaces: the geometry of thought, MIT press, Cambridge (1991).

[14] Alexander George and Daniel J. Velleman, Philosophies of Mathematics, Blackwell Publishers, Oxford (2002).

[15] Gerd Gigerenzer, Gut Feelings: The Intelligence of the Unconscious, Viking, Penguin Group (USA) Inc., (2007).

[16] Ran R. Hassin, James S. Uleman, John A. Bargh, (eds.), The New Unconscious, Oxford University Press, Oxford (2005).

[17] Nicole Van Hoeck, Patrick D. Watson, and Aron K. Barbey, 'Cognitive neuroscience of human counterfactual reasoning', Front. Hum. Neurosci. 9:420 1-18 (2015).

[18] John H. Holland, Complexity: A Very Short Introduction, Oxford University Press, Oxford (2014).

[19] Robert Kane, 'Libertarianism', in [12] (2007).

[20] Robert Kane (ed.), The Oxford Handbook of Free Will: Second Edition, Oxford University Press, Oxford (2012).

[21] Christof Koch, 'What Is Consciousness?', Nature, 557 S8-S12 (2018).

[22] Bryan Kolb and Ian Q. Whishaw, Fundamentals of Human Neuropsychology (7th ed.), Worth Publishers, New York (2015).

[23] Morten L. Kringelbach and Kent C. Berridge, 'The Affective Core of Emotion: Linking Pleasure, Subjective Well-Being, and Optimal Metastability in the Brain', Emot. Rev., July, 9(3) 191-199 (2017).

[24] Morten L. Kringelbach and Kent C. Berridge, (ed.), Pleasures of the Brain, Oxford University Press, New York (2010).

[25] Frank Krueger and Jordan Grafman, (ed.), The Neural Basis of Human Belief Systems, Psychology Press, Hove, (2013). 
[26] Avijit Lahiri, Inference Belief and Interpretation in Science, a self-published e-book, Kolkata, India (2020);

[available for download at https://philarchive.org/archive/LAHIBA http://philsci-archive.pitt.edu/17284/1/inference-belief.pdf ]

[27] Marco Leyton, 'The Neurobiology of Desire: Dopamine and the Regulation of Mood and the Motivational States in Humans', in [24].

[28] Ken Manktelow, Reasoning and Thinking, Psychology Press, Sussex (1999).

[29] Peter B. Medawar, Induction and Intuition in Scientific Thought, Methuen \& Co Ltd, London (1970).

[30] David A. Medler, 'A Brief History of Connectionism', Neural Computing Surveys, 1, 61-101 (1998).

[31] Jonathan Mercer, 'Emotional Beliefs', International Organization, 64:01, 1-31 (2010)

[32] Donald L. Nathanson, Shame and Pride: Affect, Sex, and the Birth of the Self, W.W. Norton \& Company, New York (1994).

[33] Ben R. Newell and David R. Shanks, 'Unconscious influences on decision making: A critical review', Behavioral and Brain Sciences, 37:1, 1-18 (2014).

[34] Elaine Perry, Heather Ashton, and Allan Young (ed.) Neurochemistry of Consciousness, John Benjamins Publishing Company, Amsterdam (2002).

[35] Elaine Perry, Daniel Collerton, Fiona LeBeau, and Heather Ashton, (ed.) New Horizons in the Neuroscience of Consciousness, John Benjamins Publishing Company, Amsterdam (2010).

[36] Thomas Pink, Free Will: A Very Short Introduction, Oxford University Press, Oxford (2004).

[37] Ian Ravenscroft, 'Folk Psychology as a Theory', The Stanford Encyclopedia of Philosophy (Summer 2019 Edition), Edward N. Zalta (ed.), URL = 
https://plato.stanford.edu/archives/sum2019/entries/folkpsych-theory/ .

[38] Mathieu Roy, Daphna Shohamy, and Tor D. Wager, 'Ventromedial prefrontalsubcortical systems and the generation of affective meaning, Trends Cogn Sci., 16:3, 147-156 (2012).

[39] John R. Searle, The Mystery of Consciousness, A New York Review Book, New York (1997).

[40] Steven H. Shmurak, 'Demystifying Emotion: Introducing the Affect Theory of Silvan Tomkins to Objectivists', The Journal of Ayn Rand Studies (Penn State University Press), 8:1, 1-18 (2006).

[41] Jutta Schickore and Friedrich Steinle, Revisiting Discovery and Justification: Historical and philosophical perspectives on the context distinction, Springer, Dordrecht (2006).

[42] Aaron C.T. Smith, Cognitive Mechanisms of Belief Change, Macmillan, London (2016).

[43] Chun Siong Soon, Marcel Brass, Hans-Jochen Heinze \& John-Dylan Haynes, 'Unconscious determinants of free decisions in the human brain', Nature Neuroscience, 11, 543-545 (2008).

[44] Keith E. Stanovich,Decision Making and Rationality in the Modern World, Oxford University press, oxford (2003).

[45] Henk van Steenbergen, Marie Eikemo, and Siri Leknes, 'The role of the opioid system in decision making and cognitive control: A review', Cognitive, Affective, \& Behavioral Neuroscience, 19, 435-458 (2019).

[46] Paul Thagard, 'The self as a system of multilevel interacting mechanisms', Philosophical Psychology, 27, 145-163 (2014).

[47] Stefan Thurner, Rudolf Hanel, and Peter Klimek Introduction to the Theory of Complex Systems, Oxford University Press, Oxford (2018). 
[48] Piotr Winkielman and Kent C. Berridge, 'Unconscious Emotion', Current Directions in Psychological Science, 13:3, 120-123 (2004). 